\title{
Water Mass Distribution and Ventilation Time Scales in a Cost-Efficient, Three-Dimensional Ocean Model
}

\author{
S. A. Müller, F. Joos, N. R. Edwards,* and T. F. Stocker \\ Climate and Environmental Physics, Physics Institute, University of Bern, Bern, Switzerland
}

(Manuscript received 30 May 2005, in final form 14 February 2006)

\begin{abstract}
A cost-efficient, seasonally forced three-dimensional frictional geostrophic balance ocean model (Bern3D) has been developed that features isopycnal diffusion and Gent-McWilliams transport parameterization, 32 depth layers, and an implicit numerical scheme for the vertical diffusion. It has been tuned toward observed chlorofluorocarbon (CFC-11) inventories and deep ocean radiocarbon signatures to reproduce the ventilation time scales of the thermocline and the deep ocean. Model results are consistent with the observed large-scale distributions of temperature, salinity, natural and bomb-produced radiocarbon, CFC-11, anthropogenic carbon, ${ }^{39} \mathrm{Ar} / \mathrm{Ar}$, and estimates of the meridional heat transport. Root-mean-square errors for the temperature and salinity fields are $1 \mathrm{~K}$ and $0.2 \mathrm{psu}$, comparable to results from the Ocean Carbon-Cycle Model Intercomparison Project. Global inventories of CFC-11 and anthropogenic carbon agree closely with observation-based estimates. Model weaknesses include a too-weak formation and propagation of Antarctic Intermediate Water and of North Atlantic Deep Water. The model has been applied to quantify the recent carbon balance, surface-to-deep transport mechanisms, and the importance of vertical resolution for deep equatorial upwelling. Advection is a dominant surface-to-deep transport mechanism, whereas explicit diapycnal mixing is of little importance for passive tracers and contributes less than $3 \%$ to the modeled CFC-11 inventory in the Indo-Pacific. Decreasing the vertical resolution from 32 to 8 layers causes deep equatorial upwelling to increase by more than a factor of 4. Modeled ocean uptake of anthropogenic carbon is 19.7 GtonC over the decade from 1993 to 2003, comparable to an estimate from atmospheric oxygen data of $22.4 \pm 6.1$ GtonC.
\end{abstract}

\section{Introduction}

A hierarchy of models is required to cover the spatiotemporal scales involved in ocean dynamics. Comprehensive general circulation models (GCMs) provide a relatively detailed spatiotemporal resolution of environmental phenomena (e.g., Collins et al. 2006), but their computational cost is frequently a limiting factor for both the length and variety of experiments that can be performed. On the other hand, box (e.g., Siegenthaler and Wenk 1984) or box-diffusion models (Siegenthaler and Joos 1992) are numerically efficient, but lack any ocean dynamics. Numerically efficient models such

\footnotetext{
* Current affiliation: Earth Sciences, The Open University, Milton Keynes, United Kingdom.
}

Corresponding author address: S. A. Müller, Sidlerstrasse 5, 3012 Bern, Switzerland.

E-mail: smueller@climate.unibe.ch as the 2.5-dimensional dynamical ocean models developed in the 1990s (e.g., Wright and Stocker 1991; Stocker et al. 1992) and the Hamburg Large Scale Geostrophic 3-dimensional model (Maier-Reimer et al. 1993) have been successfully applied in many carboncycle climate studies. Cost-efficient dynamical ocean models are necessary to perform millennial-scale paleoclimatic simulations (e.g., Marchal et al. 1999), systematically assess uncertainties in the climate system in a Monte Carlo framework (e.g., Edwards and Marsh 2005; Knutti et al. 2002), and to represent a wide range of tracers and processes in a coherent dynamical setting (e.g., Maier-Reimer 1993; Plattner et al. 2001; Siddall et al. 2005).

Here, a seasonally forced, dynamical, three-dimensional ocean model (Bern3D) is described that complements existing cost-efficient models. This model is tailored to realistically represent surface-to-deep exchanges of tracers and heat, to resolve the lysocline in the deep, and to represent large-scale gradients. In this respect, the model is similar to the Hamburg Large 
Scale Geostrophic model (Maier-Reimer et al. 1993; England and Maier-Reimer 2001), but is complemented with an improved mixing scheme. On the other hand, its coarse horizontal resolution $(36 \times 36$ grid boxes) does not permit either the simulation of eddies or the representation of the equatorial undercurrent system. It also does not simulate a free surface, in contrast to the Hamburg Large Scale Geostrophic model. It is suitable for integrations over many millennia, for Monte Carlo simulations, and for the representation of the marine biogeochemical cycles.

Three recent advances in ocean modeling are utilized. First, Edwards et al. (1998) and Edwards and Marsh (2005) have developed a frictional geostrophic balance dynamic ocean model with low spatial resolution. Here, we update the physical core of the model in various ways. Vertical resolution is increased from 8 to 32 layers. This allows for a better representation of thermocline and deep ocean processes and results in relatively low equatorial upwelling and a rather strong return flow of deep Pacific water into the Southern Ocean, as postulated based on oceanic tracer distributions (Key et al. 1996). An implicit numerical scheme is introduced for the diffusive vertical transport to permit a long time step of up to about 1 month. Seasonality has been implemented to resolve subannual variations in forcings, and the convection scheme has been updated. The formulations describing isopycnal mixing (Redi 1982) and eddy-induced transport (Gent et al. 1995), using the skew-flux formulation of Griffies (1998), have been separated in order to adjust the relevant parameters individually. This results in improved ventilation time scales in the Southern Ocean.

Second, the evaluation of numerical models representing the ocean has been hampered by the scarcity of oceanic observations. Recent efforts to systematically survey the spatiotemporal distribution of physical and biogeochemical tracers in the ocean have resulted in detailed global climatologies for a wide range of tracers (e.g., Levitus and Boyer 1994; Key et al. 2004). Particularly interesting to assess the time scales of ocean transport are tracers that contain time information such as radioisotopes (radiocarbon or the argon isotope ${ }^{39} \mathrm{Ar}$ ) or tracers with a time-varying, known atmospheric history such as bomb-produced radiocarbon, chlorofluorocarbons (CFCs), or anthropogenic $\mathrm{CO}_{2}$. The latter tracers have typically only penetrated the upper hundred meters of the ocean. Deeper penetration is only found in areas of deep-water formation such as the North Atlantic or parts of the Southern Ocean. Complementary to the decadal-scale information of the anthropogenic tracers, naturally produced radiocarbon, with its decay rate of $(8267 \mathrm{yr})^{-1}$, and ${ }^{39} \operatorname{Ar}\left[(388 \mathrm{yr})^{-1}\right]$ probe ocean circulation on multidecadal to multicentury time scales.

Third, within the second phase of the Ocean CarbonCycle Model Intercomparison Project (OCMIP-2) (Orr 1999) a range of data-based metrics have been developed for the evaluation of ocean circulation-marine carbon-cycle models (Doney et al. 2004; Matsumoto et al. 2004). We rely on these metrics and compare model performance relative to observations and to the models participating in the OCMIP-2. In particular, we tune the model toward a metric that includes five targets: radiocarbon in the deep Pacific, in North Atlantic Deep Water (NADW), and in the deep circumpolar waters in the Southern Ocean, as well as the CFC-11 inventories in the Indo-Pacific Ocean and in the Southern Ocean (Matsumoto et al. 2004).

In this paper, the Bern3D model physics, the implementation of ventilation time-scale tracers, and the determination of the model parameters using data-based metrics are described. The model is evaluated by comparing simulated and data-based fields for a range of water mass and ventilation tracers (temperature, salinity, CFCs, natural and bomb-produced radiocarbon, ${ }^{39} \mathrm{Ar} / \mathrm{Ar}$, and anthropogenic carbon). The model is applied to (i) calculate $\mathrm{CO}_{2}$ uptake over the industrial period; (ii) quantify the relative importance of diapycnal mixing, convection, and advection for tracer transport; and (iii) explore the impact of increasing vertical resolution on equatorial upwelling and thermohaline overturning.

In the next section, the model equations and the tracer implementation are described. Then, results of the tuning process are presented in section $3 \mathrm{a}$. In sections $3 \mathrm{~b}-\mathrm{e}$, the modeled distributions of temperature, salinity, and meridional heat transport are compared with observation-based estimates, and the seasonally varying overturning and the role of tracer transport mechanisms are discussed. The model's performance with respect to observation-based distributions and inventories of natural and bomb-produced radiocarbon, CFC- $11,{ }^{39} \mathrm{Ar} / \mathrm{Ar}$, and anthropogenic carbon is assessed in section 3f. Inventories of anthropogenic $\mathrm{CO}_{2}$ and CFCs are addressed in section 3g. Discussion and conclusions follow in section 4 .

\section{Model description}

\section{a. Physical model}

The model is based on the three-dimensional rigid-lid ocean model of Edwards et al. (1998) as updated by Edwards and Marsh (2005). The velocity field $\mathbf{u}^{\prime}$ is first diagnosed from a frictional geostrophic balance that 
can be expressed in orthogonal spherical polar coordinates ( $\phi$ : longitude, $\theta$ : latitude, $z$ : negative depth)

$$
\begin{aligned}
-f v^{\prime}+\lambda u^{\prime}-\alpha \frac{\partial \tau_{\phi}}{\partial z} & =-\frac{1}{\rho_{0} r \cos \theta} \frac{\partial p}{\partial \phi}, \\
f u^{\prime}+\lambda v^{\prime}-\alpha \frac{\partial \tau_{\theta}}{\partial z} & =-\frac{\cos \theta}{\rho_{0} r} \frac{\partial p}{\partial(\sin \theta)}, \\
\frac{\partial p}{\partial z} & =-g \rho(T, S),
\end{aligned}
$$

where $\lambda$ is a drag coefficient, $\tau$ the wind stress, $\alpha$ a scaling factor for the wind stress, $f$ the Coriolis parameter, $r$ the radius of the earth, $g$ the gravitational acceleration, and $\rho$ the local density, depending only on temperature $T$ and salinity $S$, but not on the pressure (Winton and Sarachik 1993). In this approximation small thermobaric effects are neglected. In a subsequent step, by solving

$$
\frac{\partial \mathbf{u}}{\partial t}=\frac{1}{\beta}\left(\mathbf{u}^{\prime}-\mathbf{u}\right)
$$

for the advective velocity field $\mathbf{u}$, the diagnosed velocities $\mathbf{u}^{\prime}$ are relaxed to the velocities of the previous time step using the relaxation time scale $\beta$. This improves numerical stability by suppressing the equatorial pseudo-Kelvin wave (Edwards and Shepherd 2001).

Equations (1) through (3) are solved on a uniform grid by separation of the velocity into a barotropic and a baroclinic component. The baroclinic part can be found by first eliminating the pressure, using hydrostatic balance (3). This leads to a local equation for the vertical shear as a function of the density, which is discretized using second-order centered differences, except close to boundaries where a first-order difference is used. Finally, the velocities are found by integration over depth. Following the standard procedure of Bryan (1969), the streamfunction, which defines the barotropic velocity, is found by solving a vertically integrated vorticity equation formed from Eqs. (1) and (2), in our case by direct inversion. The barotropic problem is completed by the solution of a set of constraints arising from the integral of Eqs. (1) and (2) around islands, which define the flows through straits. Owing to the absence of nonlinear momentum terms, the barotropic problem is greatly simplified compared to the primitive equations used in most GCMs. The vertical velocity $w$ then follows from the continuity equation $\operatorname{div}(\mathbf{u})=0$ The drag coefficient is increased near continental boundaries and shallow topographic features and along the equator (see caption of Table 2 for details) to suppress numerical instabilities related to pseudo-Kelvin waves (Edwards and Marsh 2005). Because the drag coefficient is nonzero, the equator is not a singular point in the model. Observed wind stress is doubled to enhance the strength of the wind-driven gyres (Edwards and Marsh 2005) that are notoriously underestimated in coarse-resolution models.

The transport equation for tracers is

$$
\frac{D}{D t} X=\operatorname{div}(\operatorname{Agrad} X)+C X+\mathrm{SMS},
$$

where $C$ stands for the convective adjustment operator and SMS represents sources minus sinks such as net air-sea fluxes or decay for radioactive tracers; $(D / D t) X$ is the material derivative of tracer $X$. The $\mathbf{u}$ of Eq. (4) is applied for advective transport using an approximation of the variable upstream-weighting scheme described by Fiadeiro and Veronis (1977). Tracer $X$ is interpolated onto the velocity points for the $n$ direction between its up- and downstream values $X_{n-}$ and $X_{n+}$ according to

$X_{n}=\frac{1}{2}\left[\left(1+\frac{\mathrm{Pec}}{|\mathrm{Pec}|+2}\right) X_{n-}+\left(1-\frac{\mathrm{Pec}}{|\mathrm{Pec}|+2}\right) X_{n+}\right]$.

Pec denotes the Peclet number defined by Pec $=u_{n} \Delta_{n} / K_{n}$, where $u_{n}$ is the velocity, $\Delta_{n}$ the grid spacing, and $K_{n}$ the diffusion coefficient for the iso- or diapycnal direction (Edwards and Marsh 2005). Weaver and Sarachick (1990) showed that the Peclet number needs to be below two in order to avoid a numerical mode in centered-difference schemes. It can easily be shown for the one-dimensional case of the discretized advectiondiffusion equation that with the upstream-weighting scheme of Eq. (6) this condition is always fulfilled.

The gradient and divergence operator in spherical polar coordinates are

$$
\begin{aligned}
\operatorname{grad} X & =\left(\frac{1}{r \cos \theta} \frac{\partial}{\partial \phi}, \frac{\cos \theta}{r} \frac{\partial}{\partial(\sin \theta)}, \frac{\partial}{\partial z}\right) X, \\
\operatorname{div} \mathbf{X} & =\left(\frac{1}{r} \frac{\partial}{\partial \phi} \frac{1}{\cos \theta}, \frac{1}{r} \frac{\partial}{\partial(\sin \theta)} \cos \theta, \frac{\partial}{\partial z}\right) \mathbf{X} .
\end{aligned}
$$

Edwards and Marsh (2005) used an explicit formulation for iso- and diapycnal diffusion and a diffusive parameterization of the eddy-induced transport following Griffies (1998), making the assumption that the coefficients for both eddy-induced transport and isopycnal mixing are equal. Here, the parameterization of the eddy-induced transport has been separated from that for isopycnal diffusion by the introduction of the two additional off-diagonal terms, vanishing in the case of equal parameters, in the mixing tensor. Here, $\mathbf{A}$ is the mixing tensor after Redi (1982) in its small-angle approximation combined with the Gent-McWilliams skew flux (Griffies 1998), 


$$
\mathbf{A}=\left(\begin{array}{ccc}
K_{I} & 0 & \left(K_{I}-\kappa\right) S_{\phi} \\
0 & K_{I} & \left(K_{I}-\kappa\right) S_{\theta} \\
\left(K_{I}+\kappa\right) S_{\phi} & \left(K_{I}+\kappa\right) S_{\theta} & K_{I} S^{2}+K_{D}
\end{array}\right),
$$

where $K_{I}$ and $K_{D}$ are the iso- and diapycnal diffusivities, $\kappa$ is the Gent-McWilliams parameter, and the local slope of the isopycnals is defined as

$$
\mathbf{S}=\left(\begin{array}{ccc}
-\frac{1}{r \cos \theta} \frac{\frac{\partial \rho}{\partial \rho}}{\partial z} & -\frac{\cos \theta}{r} \frac{\frac{\partial \rho}{\partial(\sin \theta)}}{\frac{\partial \rho}{\partial z}}, & 0
\end{array}\right) .
$$

Fluxes resulting from unrealistically steep slopes are strongly suppressed above a steepness of $\sim 2.5 \times 10^{-3}$.

The convective adjustment operator, $C$ in Eq. (5), produces the transport fluxes necessary to render the density field statically stable while conserving tracer mass. The original convection scheme of Edwards et al. (1998) mixes and combines vertically adjacent boxes representing statically unstable water masses. This tends to mix large volumes of water, especially when seasonal boundary conditions are applied. This scheme leads to an unrealistically high uptake of CFCs and other tracers from the atmosphere. Therefore, in case of instability of the uppermost layer, the upper-layer water (i.e., its tracer properties) is mixed into the deepest layer containing water of a lower density, thereby necessitating a compensating upward shift of the superimposed water. Because the layer thickness varies with depth, this upward shift involves the sequential mixing of properties from each layer into the layer above. This algorithm is repeated until the surface layer is no longer statically unstable. Finally, the original convection algorithm removes remaining instabilities in the interior of the water column.

The diagonal vertical diffusive component of the explicit advection-diffusion equation has been replaced by an implicit formulation, using previously diagnosed diffusion coefficients, to avoid disadvantageously small time steps. The diagonal term representing mixing in the $z$ direction $A^{33}$ is responsible for large vertical diffusive fluxes occurring in regions of steep isopycnal slope. A time step of around 1 month has been used with the current setup for nonseasonal test simulations. In our standard model setup with seasonal forcing, a shorter time step of about 1 week is applied to avoid damping of the seasonal signal.

Horizontal resolution is set to $36 \times 36$ grid boxes, equidistant in longitude and in the sine of latitude; thus all are of equal surface area. Thirty-two layers span the vertical range of $5000 \mathrm{~m}$ with layer spacings on a logarithmic scale ranging from $39 \mathrm{~m}$ in the uppermost layer to $397 \mathrm{~m}$ for the boxes at maximum depth. As in Ed- wards and Marsh (2005), the topography was derived by interpolation and Fourier filtering of realistic topographic data. The Bering Strait is only open to diffusive exchange, whereas the Gibraltar Strait is open to baroclinic flow also. Small basins on the ocean floor, incapable of featuring any dynamics, have been filled or smoothed by hand, and the depth of the sill between Greenland and Scandinavia has been increased to a depth of $824 \mathrm{~m}$, in order to increase NADW production. The Drake Passage has been widened and deepened in order to increase the Antarctic Circumpolar Current (ACC). In the present version, the Indonesian Passage is closed.

At the surface, model temperature and salinity are restored toward observations. Monthly restoring fields for temperature and salinity have been derived from the Levitus et al. (1994) and Levitus and Boyer (1994) datasets for a depth of $20 \mathrm{~m}$, corresponding approximately to the middepth of the uppermost layer. Values have been regridded horizontally to the model grid. A short restoring time scale for temperature and salinity of about 19.5 days has been applied to force the model to closely follow the observed seasonal cycle. Monthly wind stress climatologies from the National Centers for Environmental Prediction (NCEP)-National Center for Atmospheric Research (NCAR) reanalysis (Kalnay et al. 1996) derived data, provided by the National Oceanic and Atmospheric Administration (NOAA)Cooperative Institute for Research in Environmental Sciences (CIRES) Climate Diagnostics Center, Boulder, Colorado [available online at http://www.cdc.noaa. gov/], are applied after regridding them to the model resolution. The regridding of the temperature, salinity, and wind stress climatologies was done by calculating the area-weighted average of the input fields over each model grid box.

\section{b. Implementation of natural and bomb-produced $\Delta^{14} C,{ }^{39} \mathrm{Ar} / \mathrm{Ar}, \mathrm{CFC}-11$, and anthropogenic carbon}

Natural and bomb-produced $\Delta^{14} \mathrm{C},{ }^{39} \mathrm{Ar}, \mathrm{Ar}, \mathrm{CFC}-11$ (and CFC-12), and anthropogenic carbon have been implemented as tracers in the model. They are subject to transport according to Eq. (5).

\section{1) Sources Minus SINKS}

SMS includes air-sea transfer for all tracers in the uppermost layer and radioactive decay in the whole water column for the ${ }^{14} \mathrm{C}$ and ${ }^{39} \mathrm{Ar}$ radioisotopes. Airsea gas transfer is modeled as described in detail in the OCMIP-2 protocol (Orr et al. 1999a,b). The OCMIP-2 fields for gas transfer velocities and ice coverage and the available OCMIP-2 routines to calculate Schmidt 
numbers are used. The air-sea gas exchange rate is a function of the squared wind speed (Wanninkhof 1992), and squared wind speed fields are from satellite measurements (Orr et al. 1999a,b). For the solubility the parameterizations of Weiss (1974) for radiocarbon and anthropogenic carbon, Weiss (1970) for argon, and Warner and Weiss (1985) for CFC-11 are applied. Here, atmospheric pressure variations are neglected. Radioactive decay is included with a decay rate of (8267 $\mathrm{yr})^{-1}$ for radiocarbon and $(388 \mathrm{yr})^{-1}$ for ${ }^{39} \mathrm{Ar}$.

\section{2) RADIOCARBON}

Radiocarbon is transported in the model as the fractionation-corrected ratio ${ }^{14} R_{N}$, following Toggweiler et al. (1989a,b). (Note that ${ }^{14} R_{N}$ is transported as a concentration in $\mathrm{m}^{-3}$.) The net air-to-sea flux of ${ }^{14} R_{N}$, $F_{a \rightarrow s, \text { net }}$, is proportional to the air-sea difference in ${ }^{14} R_{N}$ and is calculated at each surface grid point according to

$$
\begin{aligned}
F_{a \rightarrow s, \text { net }}\left({ }^{14} R_{N}, t\right)= & k_{w} \frac{\operatorname{sol}(T, S) \mathrm{pCO}_{2, a}(t)}{\mathrm{DIC}_{\text {pre }}}\left[{ }^{14} R_{N, a}(t)\right. \\
& \left.-{ }^{14} R_{N, s}(t)\right] .
\end{aligned}
$$

Subscripts $a$ and $s$ refer to the atmosphere and the surface ocean. OCMIP-2 provides the spatially and seasonally varying piston transfer velocity $k_{w}\left(\mathrm{~m} \mathrm{~s}^{-1}\right)$ and the solubility of $\mathrm{CO}_{2}$, sol $\left(\mathrm{mol} \mathrm{m}{ }^{-3} \mathrm{ppm}^{-1}\right)$, is calculated after Weiss (1974) as a function of temperature $T$ and salinity $S$. Here, $\mathrm{DIC}_{\text {pre }}$ is a preindustrial reference concentration of dissolved inorganic carbon in the surface ocean, taken to be $2.0 \mathrm{~mol} \mathrm{~m}^{-3}$. Toggweiler et al. (1989b) inadvertently kept the atmospheric $\mathrm{CO}_{2}$ mixing ratio $\mathrm{pCO}_{2, a}$ constant at its preindustrial value. Here, $\mathrm{CO}_{2, a}$ is allowed to vary according to the ice-core $\mathrm{CO}_{2}$ record and direct atmospheric measurements. This approach yields similar results to that taken by OCMIP-2, where the fractionation-corrected ${ }^{14} \mathrm{C}$ concentration and total inorganic carbon are explicitly transported, because dissolved inorganic carbon varies within $\sim 10 \%$ only. Here, $\Delta^{14} \mathrm{C}$ is reported using the notation

$$
\Delta^{14} \mathrm{C}=\left(\frac{{ }^{14} R_{N}}{{ }^{14} R_{\text {std }}}-1\right) 1000 \%,
$$

with the standard ${ }^{14} \mathrm{C}$-to- ${ }^{12} \mathrm{C}$ atomic ratio ${ }^{14} R_{\text {std }}=1.176 \times$ $10^{-12}$.

\section{3) BOMB-PRODUCED RADIOCARBON}

Large amounts of radiocarbon were injected into the atmosphere by atomic bomb test explosions in the late 1950 s and early 1960s. Changes in radiocarbon concentrations, inventories, and ratios after 1954 are termed "bomb", consistent with the terminology used in obser- vation-based studies. For example, bomb $\Delta^{14} \mathrm{C}$ for this study is defined by

$$
\Delta \Delta^{14} \mathrm{C}=\Delta^{14} \mathrm{C}(t)-\Delta^{14} \mathrm{C}(1954) .
$$

\section{4) Anthropogenic CARBON}

Unlike in OCMIP, anthropogenic carbon is implemented using the perturbation approach developed by Siegenthaler and Joos (1992) and applied by Sarmiento et al. (1992). The reference value for the preindustrial atmospheric $\mathrm{pCO}_{2}$ was set to $278.0 \mathrm{ppm}$ in 1770 [and to $276.65 \mathrm{ppm}$ for the calculation starting at 1700 (Table $5)]$. Note that there is a typographic error in Eq. (10) of Sarmiento et al. (1992), whereas the original equation in Siegenthaler and Joos (1992) is correct.

\section{5) ARgon}

Both ${ }^{39} \mathrm{Ar}$ and Ar are transported individually. The ${ }^{39} \mathrm{Ar} / \mathrm{Ar}$ ratio used for comparison with data is calculated from the concentrations of the two tracers. The solubility of Ar and the Ar concentration vary strongly within the ocean. Thus, air-sea gas exchange, mixing of water masses, and decay affect the ${ }^{39} \mathrm{Ar} / \mathrm{Ar}$ ratio in a nonlinear way, and calculated ratios would be biased if the ${ }^{39} \mathrm{Ar} / \mathrm{Ar}$ ratio were implemented as a single tracer. This is not a significant issue in the case of the ${ }^{14} R_{N}$ tracer.

\section{6) AtMOSPHERIC BOUNDARY CONDITIONS FOR TRACERS}

Atmospheric tracer concentrations are prescribed in all simulations. CFC-11 concentrations for the Northern and Southern Hemisphere are taken from OCMIP-2 (Orr et al. 1999a). The northern and southern values are linearly interpolated over the region from $10^{\circ} \mathrm{S}$ to $10^{\circ} \mathrm{N}$. Radiocarbon data for three latitude bands are taken from Enting et al. (1994), as updated for OCMIP-2 (Orr et al. 1999b). Atmospheric $\mathrm{CO}_{2}$ is prescribed according to a spline fit (Enting 1987) through ice core data (Siegenthaler et al. 2005; Etheridge et al. 1996) and direct atmospheric measurements (Keeling and Whorf 1994; T. J. Conway 2004, personal communication). The atmospheric concentrations of ${ }^{39} \mathrm{Ar}$ and Ar are set to $100 \%$ modern and to 1 , respectively.

\section{7) MOdEL SPINUP}

The model was spun up for 10000 model years from rest using the seasonal fields described in section $2 \mathrm{a}$ as surface boundary conditions.

\section{Results}

\section{a. Determination of model parameters}

The model parameters as well as the restoring values for temperature and salinity in a few selected high- 
TABLE 1. Prescribed annual mean surface temperatures and salinities used to restore the model's surface temperature and salinity in specific deep-water formation areas. In all other regions seasonally varying surface values from the Levitus et al. (1994) and Levitus and Boyer (1994) datasets are applied for restoring.

\begin{tabular}{lcrc}
\hline \hline \multicolumn{1}{c}{ Location } & Lat, lon & $T\left({ }^{\circ} \mathrm{C}\right)$ & $S(\mathrm{psu})$ \\
\hline Labrador Sea & $62.7^{\circ}-70.8^{\circ} \mathrm{N}, 70^{\circ}-50^{\circ} \mathrm{W}$ & 3.2 & 34.78 \\
Around Iceland & $62.7^{\circ}-70.8^{\circ} \mathrm{N}, 30^{\circ}-10^{\circ} \mathrm{W}$ & -1.9 & 34.74 \\
Weddell Sea & $70.8^{\circ}-62.7^{\circ} \mathrm{S}, 60^{\circ}-40^{\circ} \mathrm{W}$ & -1.4 & 35.2 \\
Ross Sea & $70.8^{\circ}-62.7^{\circ} \mathrm{S}, 180^{\circ}-170^{\circ} \mathrm{W}$ & 0.0 & 34.8 \\
\hline
\end{tabular}

latitude regions were tuned to the data-based metric proposed by Matsumoto et al. (2004). The metric includes five target values each given equal weight. Parameters were determined by performing many simulations iteratively until model results reproduced the data-based metrics well within their uncertainties. Each data target represents the age or mixing time scales of an important water mass body in the deep ocean and the thermocline. The targets and their uncertainties $(1 \sigma$ for $\Delta^{14} \mathrm{C}$ ) are an average preindustrial $\Delta{ }^{14} \mathrm{C}$ signature of $-67.3 \pm 28.7 \%$ o for NADW $\left(0^{\circ}-60^{\circ} \mathrm{N} ; 1500-2500-\mathrm{m}\right.$ model depth), $-155.0 \pm 12.0 \%$ for Circumpolar Deep Water (CPDW; $90^{\circ}-45^{\circ} \mathrm{S}, 1500-5000-\mathrm{m}$ depth), and $-226.6 \pm 14.1 \%$ for North Pacific Deep Water (NPDW; $0^{\circ}-60^{\circ} \mathrm{N}, 1500-5000-\mathrm{m}$ depth), and a CFC-11 inventory of $1.97 \times 10^{8} \mathrm{~mol} \pm 10 \%$ for the Indo-Pacific Ocean $\left(40^{\circ} \mathrm{S}-\right.$ $\left.90^{\circ} \mathrm{N}\right)$ and $1.42 \times 10^{8} \mathrm{~mol} \pm 10 \%$ for the Indo-Pacific part of the Southern Ocean $\left(90^{\circ}-40^{\circ} \mathrm{S}\right)$ evaluated for the World Ocean Circulation Experiment (WOCE) era.

The restoring fields for temperature and salinity were used as tuning parameters in the source regions of NADW and Antarctic Bottom Water (AABW) similar to the procedure used by Hirst and Cai (1994) (Table 1). This was done to force the formation of deep water with realistic temperatures and salinities, and hence densities. A known problem when restoring toward climatological surface values for temperature and salinity is that the observed densities of NADW and AABW have no counterpart in the climatological surface data. This means that the formation of AABW and NADW with a temperature, salinity, and density signature close to observations, regridded onto the coarse-resolution model grid, is not to be expected without modification of the prescribed climatological surface values. Temperatures and salinities in the Labrador Sea and around Iceland (the source regions for NADW), and in the Ross and in the Weddell Seas (the source regions for $\mathrm{AABW}$ ) were set to observation-based annual mean values for newly formed deep-water masses. Restoring values were modified in seven boxes representing the respective regions, and those values were kept constant throughout the year, that is, without the seasonal cycle.
The radiocarbon and CFC-11 targets were matched within their uncertainties (Fig. 1). Most models participating in OCMIP-2 simulate radiocarbon signatures and CFC-11 inventories that deviate by more than one standard deviation (10\% for CFC- 11$)$ from the observations (Fig. 1). The tuning process resulted in the parameter values shown in Table 2 and the modified restoring values are given in Table 1. A ratio of 1:2 for the parameters representing isopycnal transport and GentMcWilliams subgrid-scale transport in combination with a low diapycnal diffusivity were found to produce results close to the target values.

\section{b. Circulation}

The annual mean overturning streamfunction (Fig. 2) displays the clockwise overturning associated with NADW and anticlockwise overturning in the deep Pacific and the lowest layers of the Atlantic. The annual mean maximum overturning transport of NADW reaches almost $14.0 \mathrm{~Sv}\left(1 \mathrm{~Sv} \equiv 10^{6} \mathrm{~m}^{3} \mathrm{~s}^{-1}\right)$ in the deep North Atlantic of which $10.7 \mathrm{~Sv}$ are transported across the equator, compared to the data-based estimate of 17 Sv by Ganachaud and Wunsch (2000). The penetration of NADW is too shallow as indicated, for example, by a much-stronger-than-observed vertical gradient in radiocarbon between 2000 and $3000 \mathrm{~m}$. The deep Atlantic below $3000 \mathrm{~m}$ is weakly ventilated from the south. A strong clockwise overturning cell is simulated between about $71^{\circ}$ and $36^{\circ} \mathrm{S}$ with a net near-surface northward transport of $37.1 \mathrm{~Sv}$ at $51.1^{\circ} \mathrm{S}$. This cell extends to a depth of almost $1000 \mathrm{~m}$. The total overturning in the Southern Ocean is dominated by advective transport, partly compensated by eddy-induced transport of up to 34.7 Sv. Around 11.4 Sv enter the Pacific below $2100 \mathrm{~m}$ at $30^{\circ} \mathrm{S}, 7.4 \mathrm{~Sv}$ of which return to the Southern Ocean between 481 and $2100 \mathrm{~m}$. Deep equatorial upwelling, generally found to be too strong in coarse-resolution models, is relatively modest with about $4 \mathrm{~Sv}$.

Large seasonal variations in the overturning streamfunction (Fig. 3) are simulated in response to the seasonally varying wind stress and surface restoring fields for temperature and salinity. The difference between winter and summer overturning is characterized by wind-induced cells that extend from the surface to the bottom in agreement with results of other seasonally forced 2.5- and three-dimensional models (Schmittner and Stocker 2001; Nakano et al. 1999).

The model represents the wind-driven gyres at the surface and in the upper thermocline. However, simulated gyre transport is too weak, probably related to the relatively strong frictional drag applied. For example, the Drake Passage throughflow is only around $48 \mathrm{~Sv}$ 
(a) Natural $\Delta^{14} \mathrm{C}$

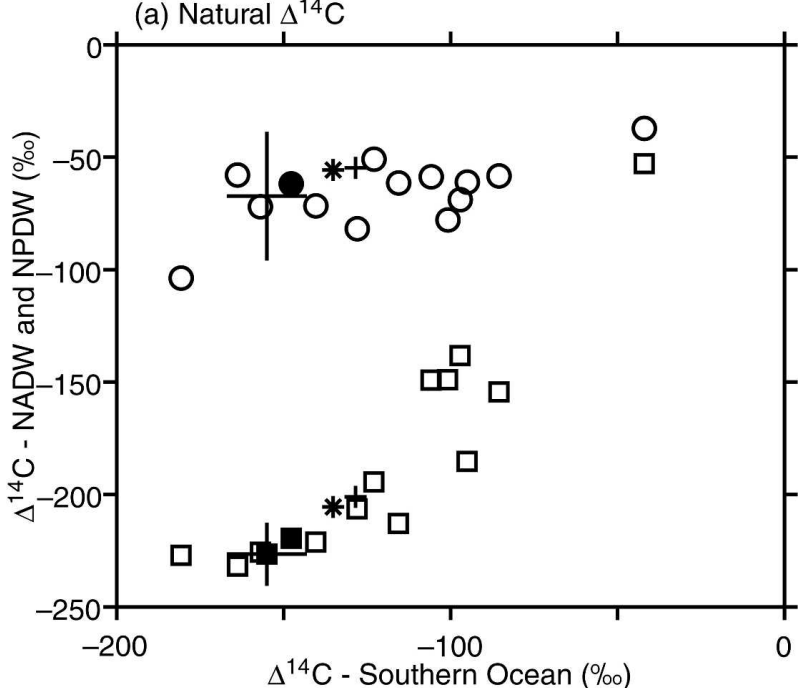

(b) CFC-11 Inventory

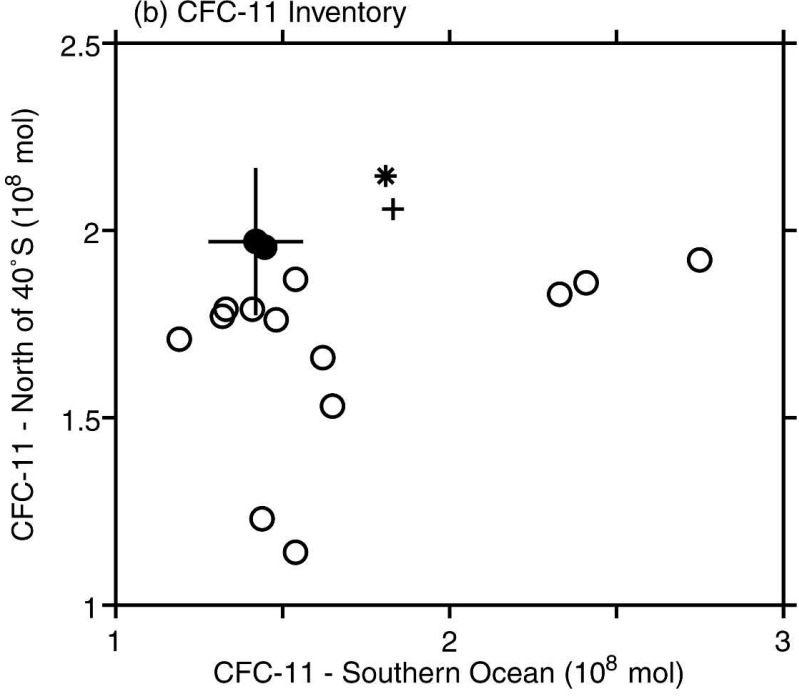

FIG. 1. (a) Radiocarbon signatures of North Atlantic Deep Water (circles) and North Pacific Deep Water (squares) vs Circumpolar Deep Water as estimated from observations (filled with error bars) and simulated with the Bern3D model (filled) and the models participating in the OCMIP-2 (open symbols). Error bars are one standard deviation of the observation-based estimate. (b) As in (a), but for the inventories of CFC-11 in the Pacific and Indian Oceans north of $40^{\circ} \mathrm{S}$ and the Indo-Pacific sector of the Southern Ocean (south of $40^{\circ} \mathrm{S}$ ). Error bars in (b) denote a \pm $10 \%$ uncertainty. The five observation-based estimates have been used as target values to tune the parameters of the Bern3D model and are matched within their uncertainties. The star represents a simulation where the Gent-McWilliams parameter is set equal to the isopycnal diffusivity $\left(1000 \mathrm{~m}^{2} \mathrm{~s}^{-1}\right)$ and the plus sign indicates a run with the original convection scheme of Edwards et al. (1998) applied. In both simulations CFC-11 inventories in the Southern Ocean are much larger than observed, whereas the simulated values for the other targets are only modestly modified compared to the standard model setup.
TABLE 2. Model parameters of the standard version obtained by tuning the model to a data-based metric. The drag coefficient $\lambda$ is set at the points defining the barotropic streamfunction with the value given in the table and is increased by a factor of 6.25 closest to topographic features above $1158 \mathrm{~m}$ and by a factor of 2.5 at their neighboring points. At and one row away from the equator the drag coefficient is also increased by a factor of 6.25 (2.5 for points two rows away from the equator). This field for the drag coefficient is interpolated onto the respective velocity points. The relaxation time scale $\beta$ is related to the relaxation parameter $r$ defined by Edwards and Shepherd (2001), $\beta=r \cdot \Delta t /(1-r)$; here $r=0.85$.

\begin{tabular}{lc}
\hline \hline \multicolumn{1}{c}{ Parameter } & \multicolumn{1}{c}{ Value } \\
\hline Isopycnal diffusivity & $1000 \mathrm{~m}^{2} \mathrm{~s}^{-1}$ \\
Gent-McWilliams parameter & $2000 \mathrm{~m}^{2} \mathrm{~s}^{-1}$ \\
Diapycnal diffusivity & $10^{-5} \mathrm{~m}^{2} \mathrm{~s}^{-1}$ \\
Friction & $0.5 \mathrm{days}^{-1}$ \\
Wind stress scaling & 2 \\
Velocity relaxation time scale & 43.1 days \\
Time step & $(48)^{-1} \mathrm{yr}$ \\
\hline
\end{tabular}

compared to the data-based estimate of $140 \mathrm{~Sv}$ by Ganachaud and Wunsch (2000).

\section{c. Sensitivity of model results to mixing parameterization, convection scheme, and vertical resolution}

The modifications of the original code by Edwards et al. (1998) described in section 2a appear to be crucial in matching the five target values specified to probe the ventilation time scales of important water masses. In particular, the Southern Ocean CFC-11 inventory is sensitive to the choice of the Gent-McWilliams and eddy diffusion parameters and the convection scheme. This is illustrated by two simulations where either the original convection scheme was applied or the GentMcWilliams parameter was set to be equal to the isopycnal diffusivity. In both simulations Southern Ocean CFC-11 inventories are much higher than those observed (Fig. 1). The separation of the isopycnal parameter from the Gent-McWilliams parameter allows one to tune the balance between the advective overturning and the counteracting eddy-induced overturning in the Southern Ocean (shown as counterclockwise in Fig. 2d, the resulting balance is shown by the clockwise overturning cell in Fig. 2c). Convection in the Southern Ocean is too vigorous in simulations where the original convection scheme of Edwards et al. (1998) is applied as large bodies of water are homogenized by mixing adjacent boxes, whereas the slotting of dense (surface) water at the depth where water of equal in situ density is found, mimics the convection process resulting from brine rejection. 
(a) Atlantic: Meridional Overturning

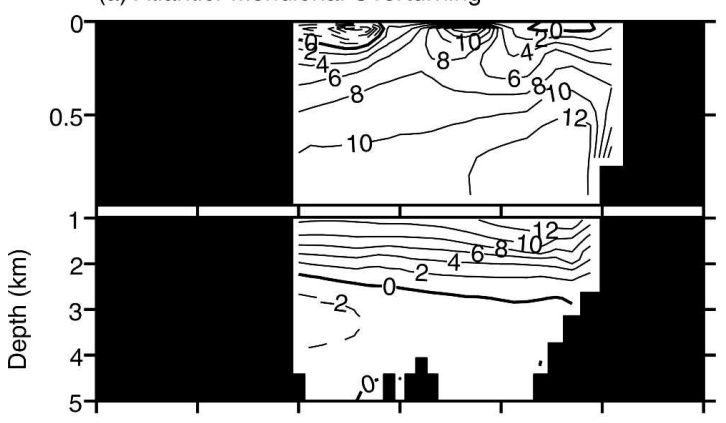

(c) Global Ocean: Meridional Overturning

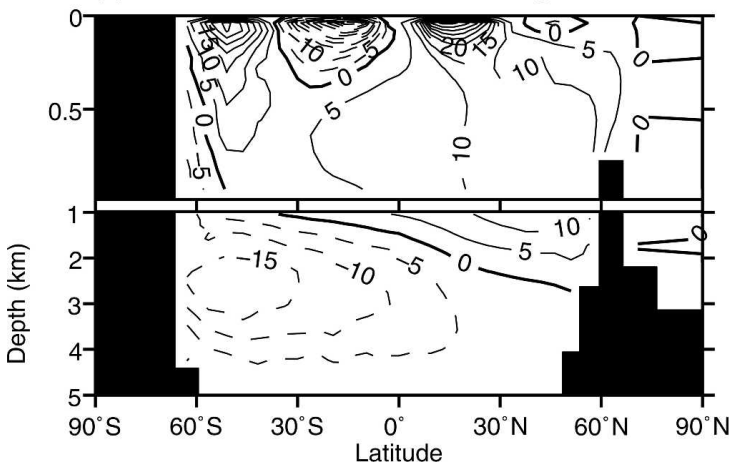

(b) Pacific: Meridional Overturning

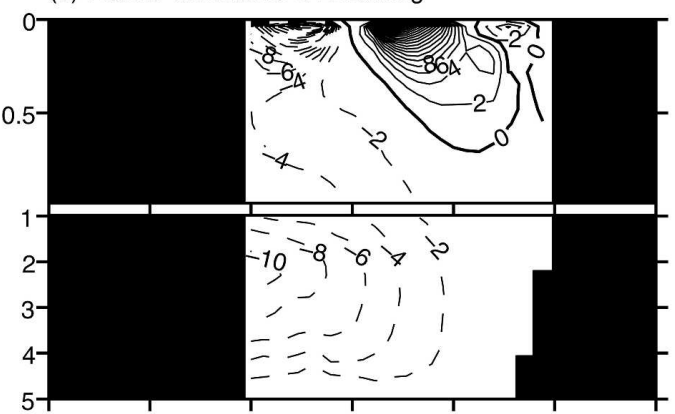

(d) Global Ocean: Gent-McWilliams Overturning

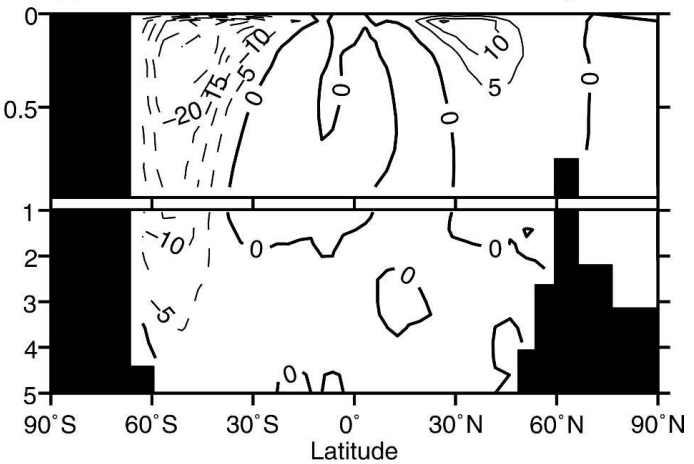

FIG. 2. Annual mean overturning streamfunctions (including contribution resulting from Gent-McWilliams transport) for the (a) Atlantic, (b) Pacific, and (c) global ocean, and the contribution resulting from (d) Gent-McWilliams transport only; contour labels in Sv.

Increasing the vertical resolution from 8 to 32 layers leads to a significant reduction in deep equatorial upwelling and overturning strengths (Fig. 4). In a set of idealized experiments, vertical resolution was increased stepwise from 8 to 16 to 24 to 32 layers, but the simplified bottom topography was unchanged (note that the standard model solution is substantially different from the results obtained with 32 layers and the simplified

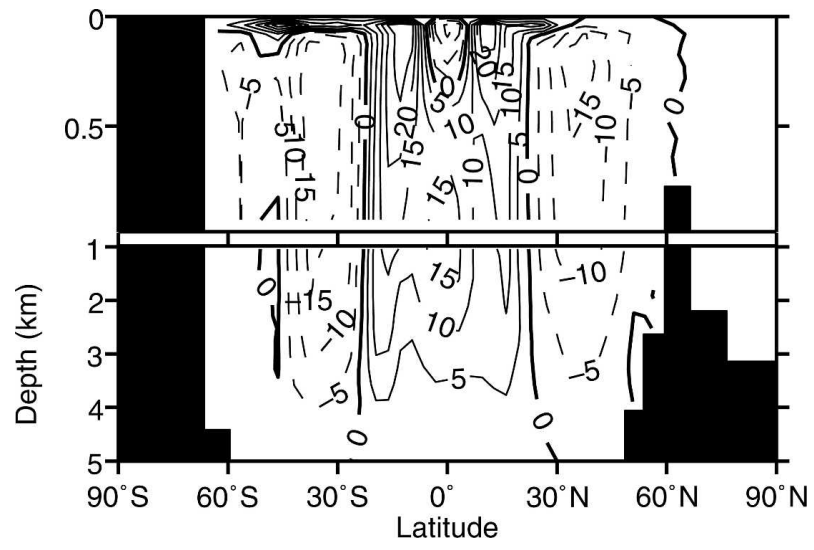

FIG. 3. Seasonality of the global overturning streamfunction. Average during winter (November-April) minus average during summer (May-October); contour interval is $5 \mathrm{~Sv}$. topography). The Atlantic overturning, Drake Passage throughflow, and deep equatorial upwelling in the $\mathrm{Pa}$ cific appear to converge toward final solutions with increasing resolution. This suggests that at a resolution of 32 layers, the large-scale circulation depends only weakly on vertical numerical diffusivity. Pacific upwelling decreases by more than a factor of 4 from about 23 to about $5 \mathrm{~Sv}$ when the resolution is increased from 8 to 32 layers. North Atlantic overturning is reduced from 15 to $8 \mathrm{~Sv}$, and Drake Passage throughflow from 55 to $37 \mathrm{~Sv}$. A small, deep equatorial upwelling is crucial in biogeochemistry models to minimize nutrient trapping in the equatorial thermocline and to avoid unrealistically high biological production around the equator. A fine vertical resolution is also important to drive a return flow from the deep Pacific into the Southern Ocean, as evidenced by the observed tracer distribution.

\section{d. Tracer transport mechanisms}

Next, we quantify the role of diapycnal mixing, advection and convection, and explicit diffusion for the modeled CFC-11 inventories and the deep Pacific radiocarbon signature (Fig. 5). The diapycnal-mixing coefficient varied between 0 and $10^{-4} \mathrm{~m}^{2} \mathrm{~s}^{-1}$ for the pas- 

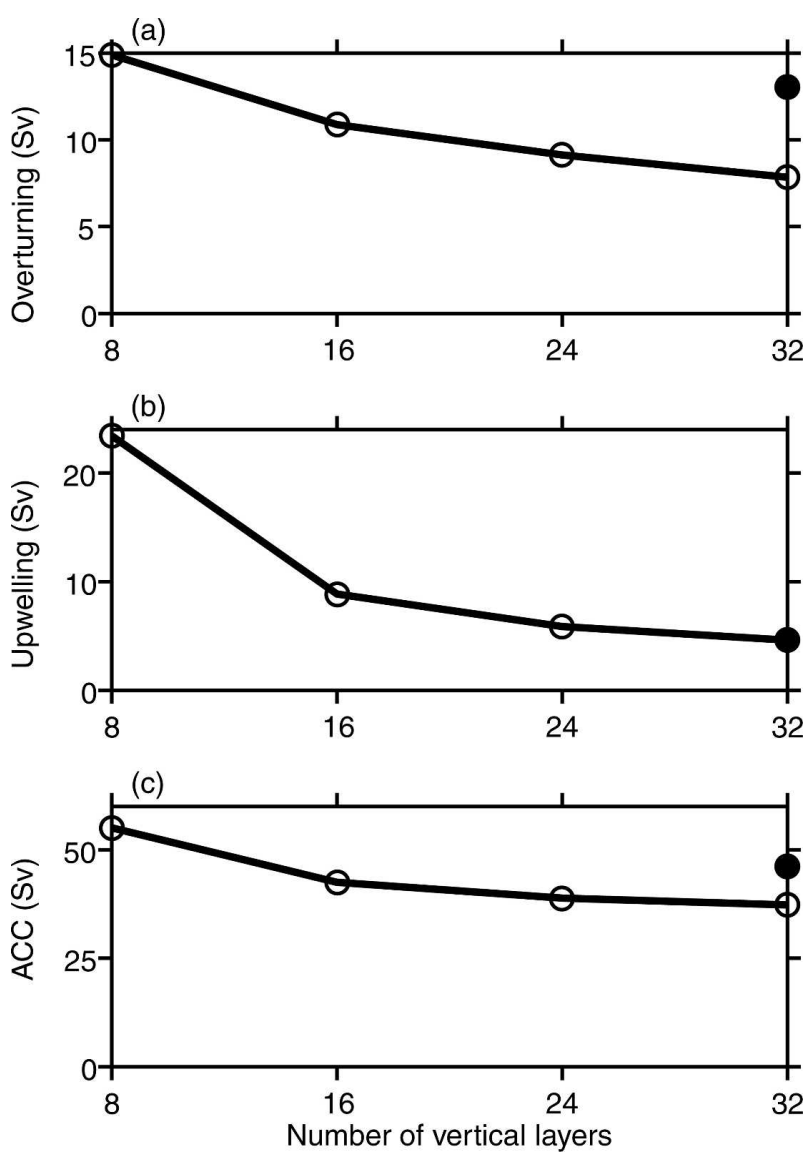

FIG. 4. Impact of resolution on the (a) maximum Atlantic overturning, and (b) deep equatorial upwelling in the Pacific and (c) Drake Passage throughflow (results shown are without the eddyinduced transport included). Deep equatorial upwelling is defined here as the value of the streamfunction at the saddle point between the two counterclockwise-turning cells in the deep Pacific (see Fig. 2b). Note that the standard model solution (filled circles) is substantially different from the results obtained with 32 layers and the simplified topography.

sive tracers CFC-11 and radiocarbon, whereas diffusivities for temperature and salinity and thus circulation were kept constant. In a further simulation, convection was turned off for the two passive tracers and diapycnal mixing was set to its standard value $\left(10^{-5} \mathrm{~m}^{2} \mathrm{~s}^{-1}\right)$ for all tracers.

For the standard model setup $\left(K_{d}=10^{-5} \mathrm{~m}^{2} \mathrm{~s}^{-1}\right)$, transport by advection (with possible contributions from numerical diffusion) largely dominates modeled CFC-11 inventories and deep ocean radiocarbon signatures. The role of convection is substantial for the modeled CFC-11 inventory, but minor for the simulated NPDW radiocarbon signature. For example, transport by convection contributes about $23 \%$ to the modeled CFC-11 inventory in the Indo-Pacific sector of the Southern Ocean and $9 \%$ to the CFC-11 inventory in the
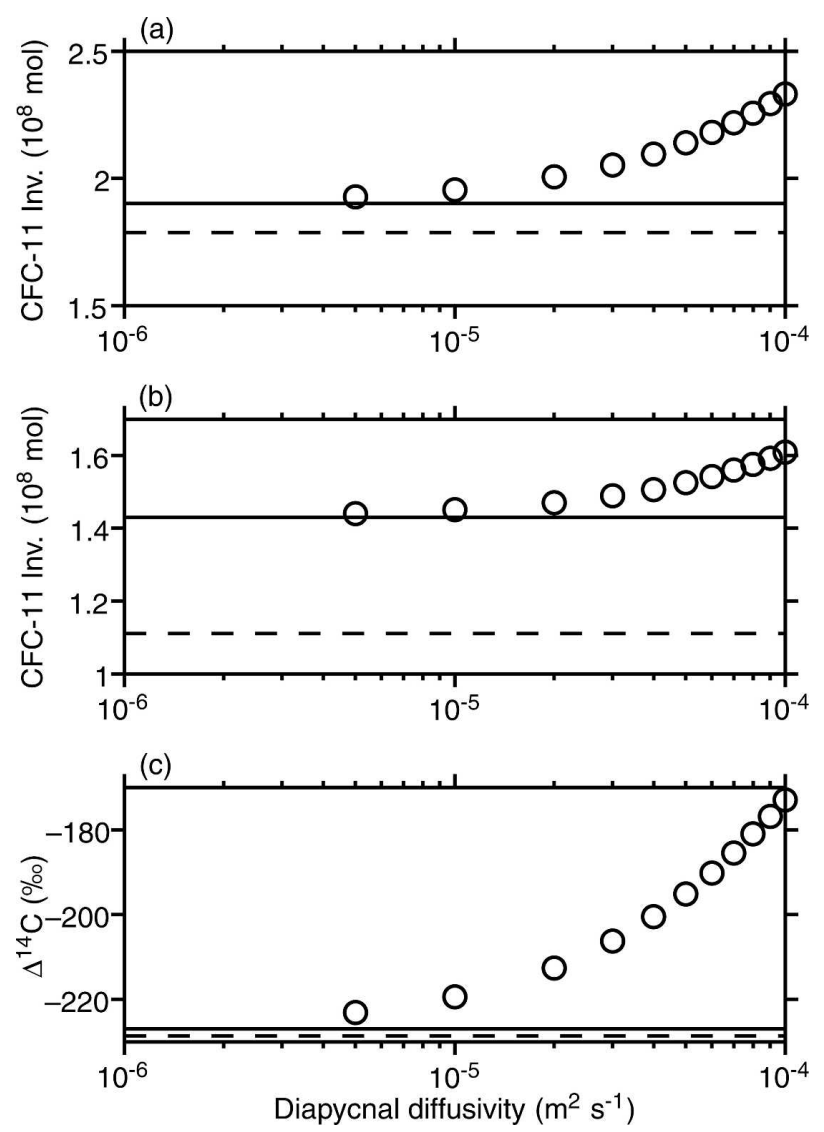

FIG. 5. Importance of different surface-to-deep transport mechanisms for (a) the CFC-11 inventory in the Indo-Pacific (north of $40^{\circ} \mathrm{S}$ ), (b) the Southern Ocean section of the IndoPacific (south of $40^{\circ} \mathrm{S}$ ), and (c) the radiocarbon signature of the NPDW. The diapycnal diffusion coefficients for CFC-11 and ${ }^{14} \mathrm{C}$ only were varied between zero (solid line), and between $5 \times 10^{-6}$ and $10^{-4} \mathrm{~m}^{2} \mathrm{~s}^{-1}$ (open circles); convection for CFC-11 and ${ }^{14} \mathrm{C}$ was turned off in a simulation with the diapycnal coefficients set to the standard value of $10^{-5} \mathrm{~m}^{2} \mathrm{~s}^{-1}$ (dashed line).

Indo-Pacific, but convection alters NPDW radiocarbon only by about $1 \%$. Diapycnal mixing contributes less than $3 \%$ to the simulated CFC-11 inventory in the Indo-Pacific, both north of $40^{\circ} \mathrm{S}$ and in the Southern Ocean sector. Similarly, the NPDW ${ }^{14} \mathrm{C} /{ }^{12} \mathrm{C}$ signature is decreased by less than $1 \%$ (about $8 \%$ in $\Delta^{14} \mathrm{C}$ ) if the diapycnal-mixing coefficient is set to zero. The different role of convection for CFC-11 and radiocarbon can be understood by the difference in atmospheric boundary and surface-to-deep gradients in convective regions for the two tracers. CFC-11 is increasing over the industrial period and large surface-to-deep gradients are found in convective regions, whereas atmospheric radiocarbon varied relatively little (it is kept constant in the model) and surface-to-deep gradients in the Southern Ocean are relatively small. 
The influence of diapycnal mixing on the CFC-11 inventories and the age of the NPDW becomes significant for a higher diapycnal diffusion coefficient. With a coefficient of $10^{-4} \mathrm{~m}^{2} \mathrm{~s}^{-1}$, transport by diapycnal mixing contributes up to about $19 \%$ to the modeled CFC11 inventories and about $7 \%$ to the ${ }^{14} \mathrm{C} /{ }^{12} \mathrm{C}$ ratio in NPDW.

\section{e. Simulated versus observed temperature, salinity, and heat transport}

The model represents the important water masses of the World Ocean. Simulated temperature and salinity fields agree well with observations (Fig. 6). The rootmean-square differences between modeled and observation-based (Levitus and Boyer 1994; Levitus et al. 1994) annual mean values are $1.0^{\circ} \mathrm{C}$ for temperature and 0.20 psu for salinity. This is comparable to the rootmean-square differences of the prognostic models participating in the OCMIP-2 (Fig. 7). The standard deviations of the simulated annual mean fields are very close to observations and correlation between model results and observations are high (Fig. 8). A more detailed comparison reveals that the simulated tongues of fresh and cold Antarctic Intermediate Water (AAIW) do not extend deep enough and far enough toward the equator in the Pacific, Indian, and Atlantic Oceans. The largest deviations between modeled and observed temperatures are found in the thermocline. In general, the model's thermocline is somewhat too warm, but lower-thanobserved temperatures are found in the shallow equatorial Pacific and Indian Ocean and at 500-m depth in the South Atlantic around $30^{\circ} \mathrm{S}$. In the deep Pacific and Indian Oceans, temperatures agree within a few tenths of a degree Celsius with observation, and salinity is slightly higher (0.1-0.2 psu) than that observed. In the deep Atlantic, modeled salinity agrees within 0.1 psu with observations. Temperatures are close to observation in the simulated core of the NADW but are too cold by up to about $1.5^{\circ} \mathrm{C}$ at depths below $2000-3000 \mathrm{~m}$. In the Atlantic sector of the Southern Ocean modeled salinity is higher than observed by $0.2-0.3$ psu below $2500 \mathrm{~m}$ and temperatures are slightly too warm.

Simulated meridional heat transport (Fig. 9) broadly agrees with data-based estimates (Trenberth and Caron 2001). Meridional heat transport is directed poleward in both hemispheres with extrema of slightly less than 2 PW. Heat transport is directed northward in the entire Atlantic (north of $34^{\circ} \mathrm{S}$ ) and reaches a maximum of 0.92 $\mathrm{PW}$ around $18^{\circ} \mathrm{N}$. The simulated meridional heat transport in the Atlantic is at the lower end or below the data-based estimates. This is to be expected because simulated NADW formation is weak. In the Pacific, simulated meridional heat transport is poleward in both hemispheres and its magnitude agrees well with the few data-based estimates.

\section{f. Simulated versus observed distributions of ventilation time-scale tracers}

Now we address the distribution of a range of tracers that carry information on ventilation time scales. The subsurface distribution of salinity and temperature analyzed in the previous subsection is governed by the balance of advection, convection, and diffusion. A distribution of temperature and salinity close to observations may be achieved even when ventilation is too vigorous or too weak. In contrast, the radioactive tracers ${ }^{14} \mathrm{C}$ and ${ }^{39} \mathrm{Ar}$ and the transient tracers $\mathrm{CFC}-11$, bomb-produced ${ }^{14} \mathrm{C}$, and anthropogenic carbon explicitly probe the ventilation time scale. The time information comes either from the radioactive decay in case of the radioisotopes or the time-varying atmospheric concentration in case of the three anthropogenic tracers. We expect that the model tuning toward CFC-11 inventories of the Southern Ocean and the Indo-Pacific Ocean and to the radiocarbon signatures of the deep-water mass bodies CPDW, NPDW, and NADW has led to realistic average ventilation time scales for the thermocline and the deep ocean. This is further examined using transient tracers and analyzing spatial distributions in more detail. The Global Ocean Data Analysis Project (GLODAP) climatology is a powerful tool for model evaluation and results for radiocarbon, CFCs, and anthropogenic carbon are compared with the gridded GLODAP data (Key et al. 2004). The ${ }^{39} \mathrm{Ar} / \mathrm{Ar}$ data are sparse and are taken from Rodriguez (1993).

Each of the investigated tracers has its particular strength to probe ocean circulation and ventilation time scales. The transient tracers CFC-11, bomb-produced radiocarbon, and anthropogenic $\mathrm{CO}_{2}$ are ideal to probe decadal-scale transport processes. These tracers have penetrated only the upper kilometer in most regions of the world and are particularly useful to evaluate the surface-to-deep exchange in the thermocline. Differences between these tracers arise from different atmospheric histories and different sensitivities to gas exchange. Atmospheric $\mathrm{CO}_{2}$ and $\mathrm{CFC}-11$ have increased roughly exponentially during the past $200 \mathrm{yr}$ and the past decades. The atmospheric ${ }^{14} \mathrm{C}$ concentration almost doubled within a decade before the bomb-test ban treaty was set in place in 1963. Since then, the atmospheric $\Delta^{14} \mathrm{C}$ signal has decreased as bomb-produced radiocarbon is taken up by the ocean and the land biosphere, and because of the release of radiocarbon-free fossil carbon. The equilibration time of a surface layer 
(a) Atlantic: Model Temperature

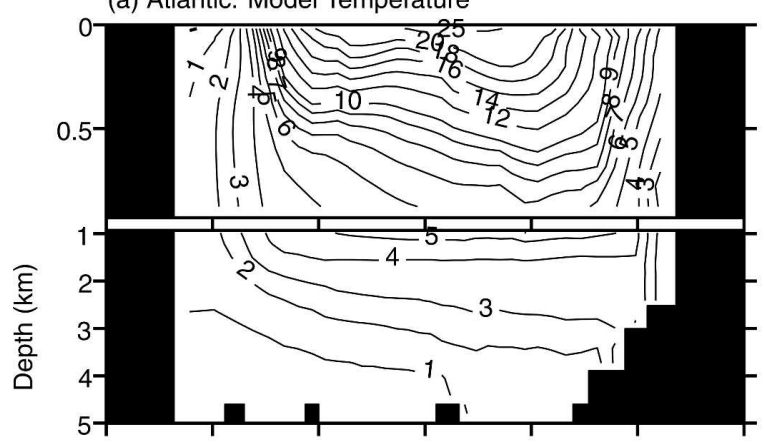

(c) Atlantic: Model Salinity

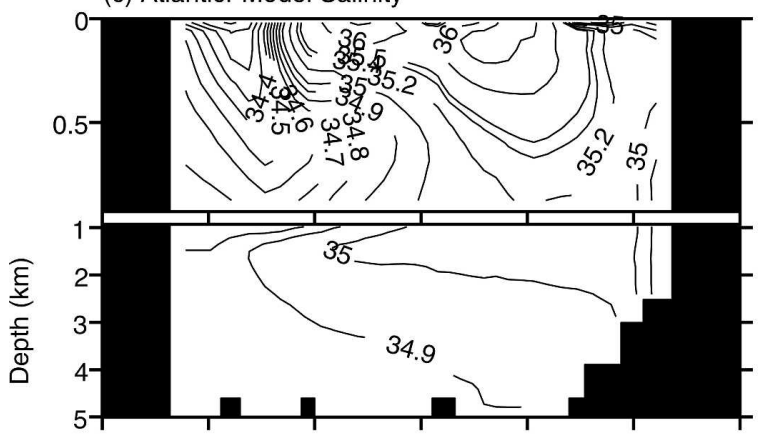

(e) Pacific: Model Temperature - Pacific

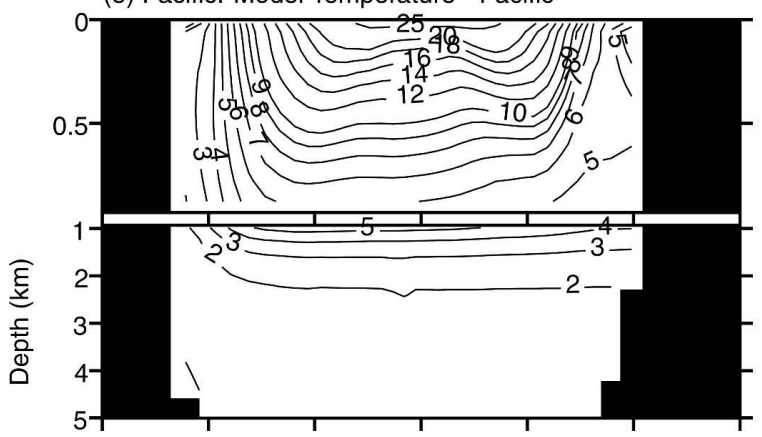

(g) Pacific: Model Salinity

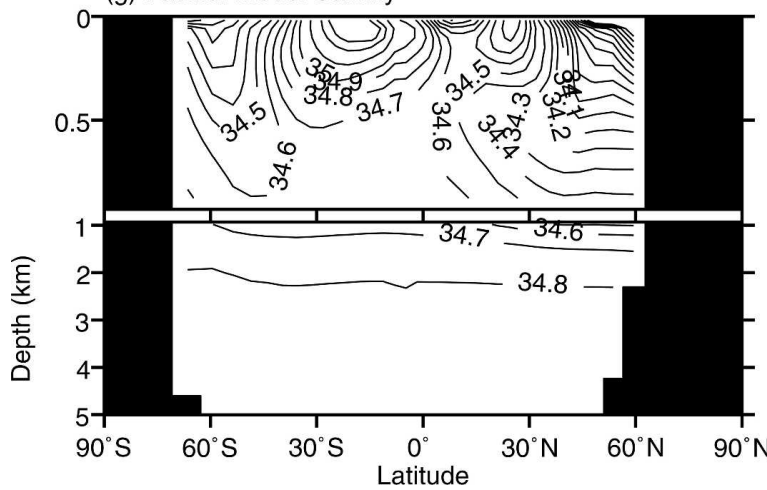

(b) Atlantic: Model - Data Temperature

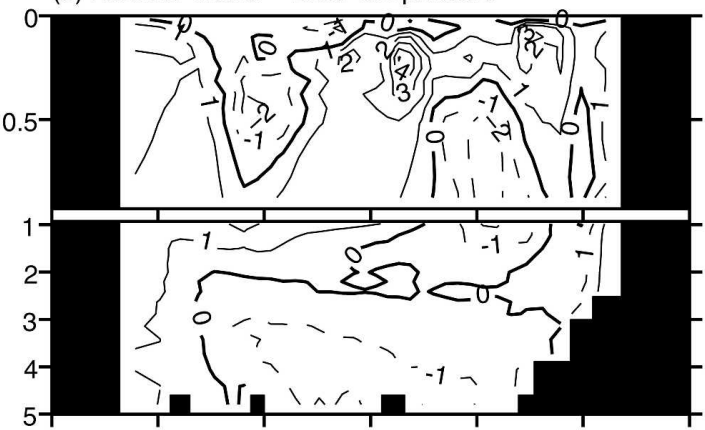

(d) Atlantic: Model - Data Salinity

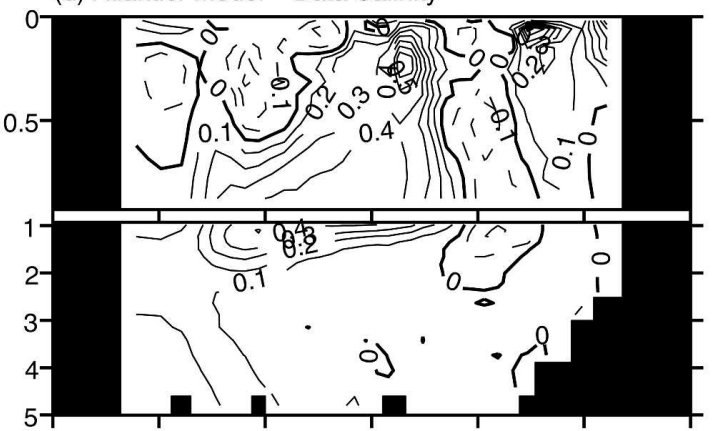

(f) Pacific: Model - Data Temperature

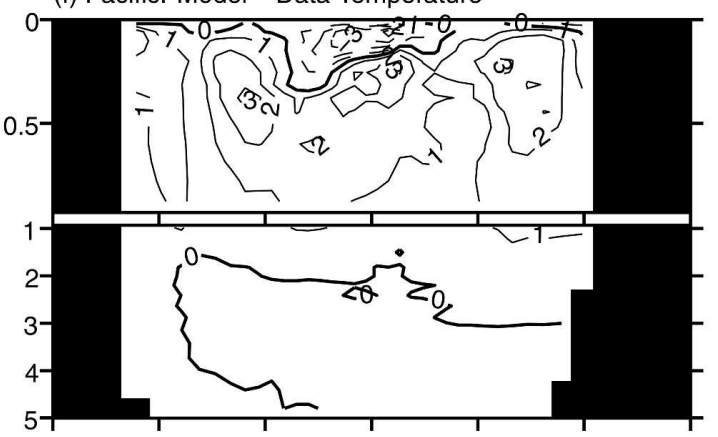

(h) Pacific: Model - Data Salinity

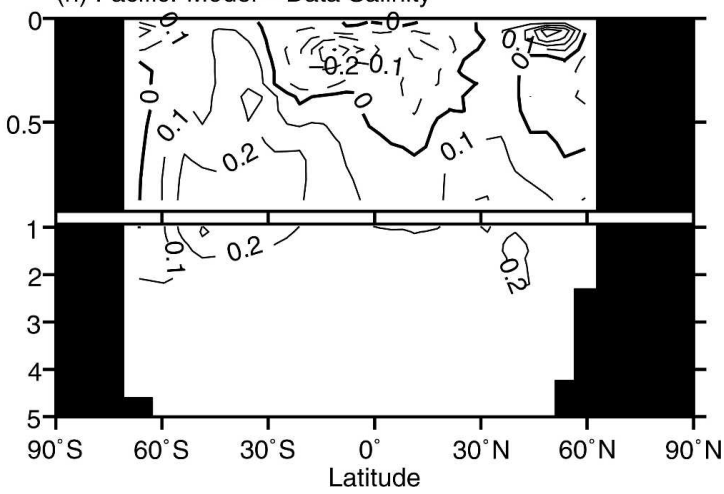

FIG. 6. (a), (c), (e), and (g) Modeled annual and zonal mean cross sections for temperature $\left({ }^{\circ} \mathrm{C}\right)$ and salinity (psu) in the Atlantic and Pacific, and (b), (d), (f), and (h) their differences with respect to the Levitus datasets (Levitus and Boyer 1994; Levitus et al. 1994). 


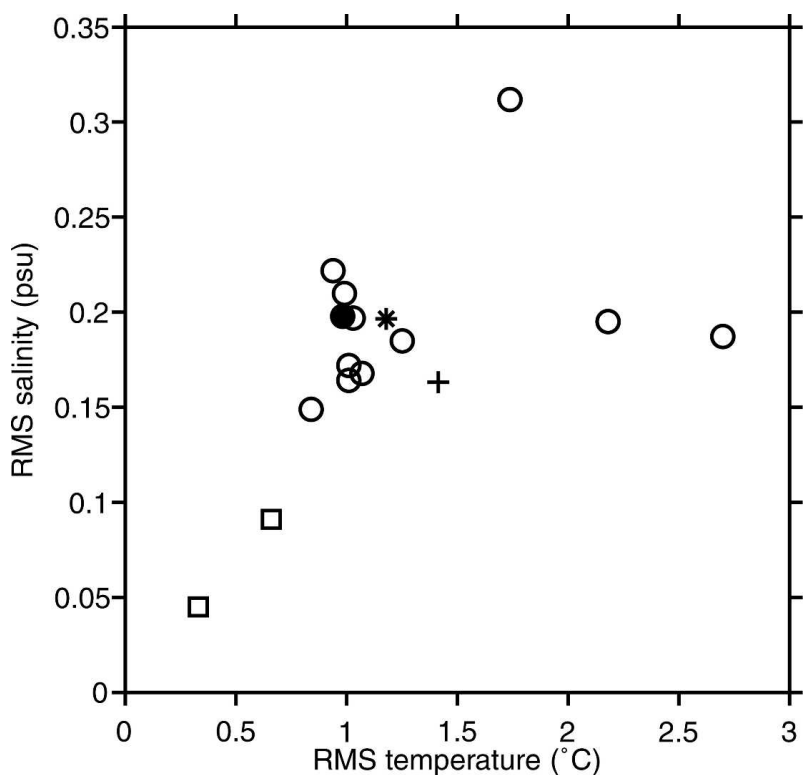

FIG. 7. Root-mean-square difference between model results and data (Levitus et al. 1994; Levitus and Boyer 1994) for temperature and salinity for the Bern3D model (filled) and the OCMIP-2 models (open symbols, circles denote prognostic, squares inverse models). The star shows the result of a simulation where the GentMcWilliams parameter is set equal to the isopycnal diffusivity $\left(1000 \mathrm{~m}^{2} \mathrm{~s}^{-1}\right)$ and the plus sign indicates a model run where the original convection scheme of (Edwards et al. 1998) was used.

with a typical depth of $70 \mathrm{~m}$ with the atmosphere by gas exchange is about a month for CFC-11, one year for $\mathrm{CO}_{2}$, and a decade for radiocarbon. Natural radiocarbon with its mean lifetime of $8267 \mathrm{yr}$ is ideal to probe century-to-millennial time-scale processes, and ${ }^{39} \mathrm{Ar}$ with its mean life time of $388 \mathrm{yr}$ is well suited for decadal-to-century time scales.

The comparison between simulated and data-based average basin profiles reveals that overall the time scales of surface-to-deep transport are realistic in the model (Fig. 10). First, transport across the thermocline is addressed. The observation-based profiles of CFC11, bomb-produced radiocarbon, and anthropogenic carbon are matched in the Pacific and, except for bombproduced radiocarbon, in the Southern Ocean. Simulated anthropogenic carbon is somewhat higher in the surface Pacific than suggested by the data. This might be related to uncertainties associated with our perturbation approach for $\mathrm{CO}_{2}$ because simulated basinaveraged surface values do agree with observations for CFC-11 and bomb-produced radiocarbon. The model underestimates the average concentration of CFC-11 and anthropogenic carbon in the thermocline of the Atlantic, and to a smaller extent in the Indian Ocean. The few available argon data are well matched in the

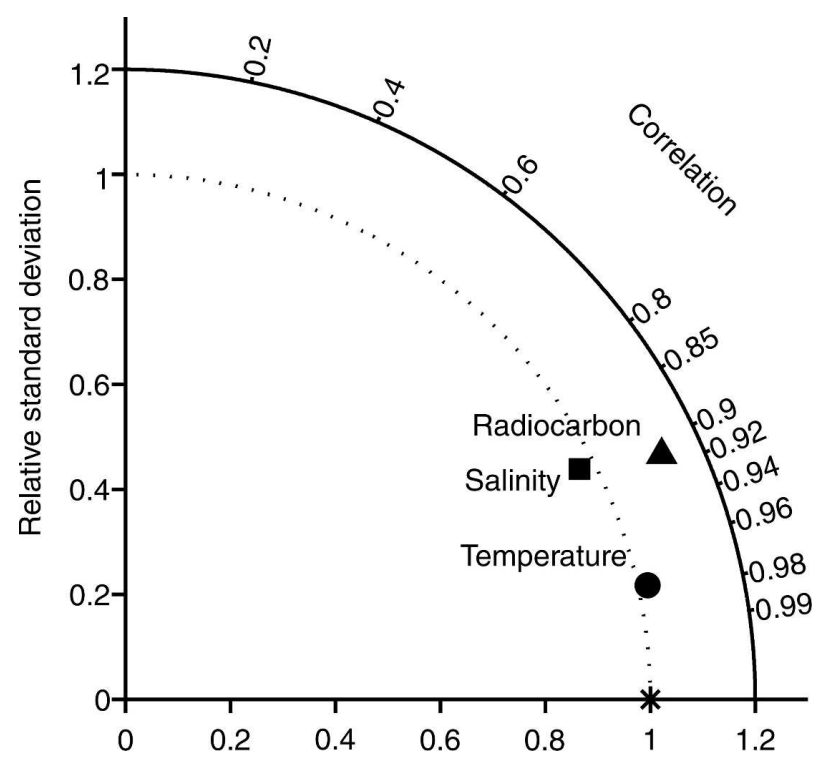

FIG. 8. Taylor diagram showing the correlation and the relative standard deviation for modeled annual mean temperature, salinity, and background $\Delta^{14} \mathrm{C}$ fields in comparison to Levitus and Boyer (1994) and Levitus et al. (1994) and GLODAP (Key et al. 2004) data fields. The star indicates the position in the diagram of a perfect agreement with the data fields.

upper Pacific and Southern Ocean. Data are too sparse in the upper Atlantic and Indian to draw conclusions for basin-averaged properties. The data-based profiles of natural (preindustrial) radiocarbon are well matched

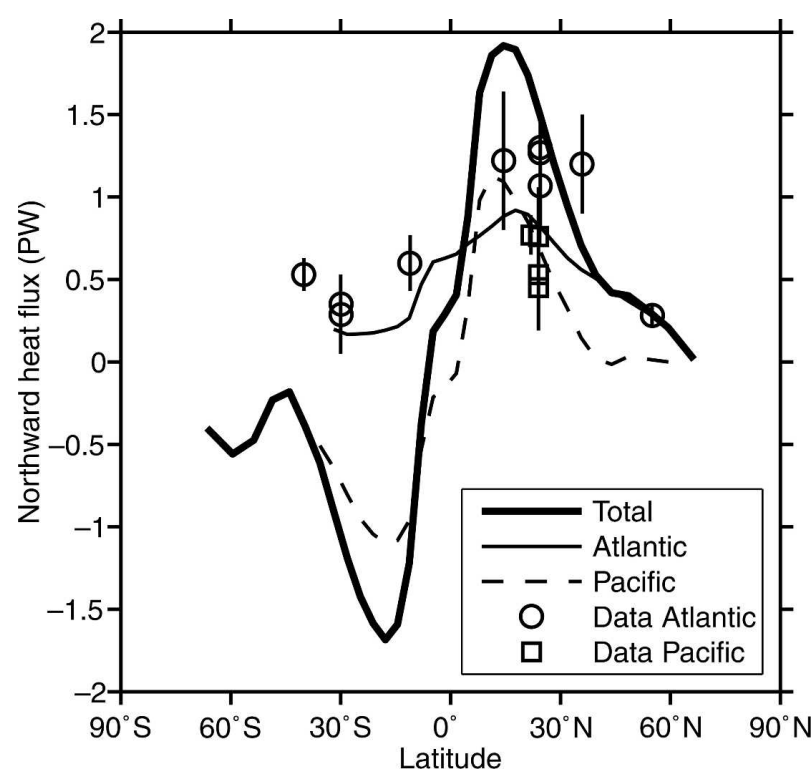

FIG. 9. Annual mean meridional heat transport in PW $\left(10^{15} \mathrm{~W}\right)$. Modeled heat transport is shown by lines; open symbols represent the data-based estimates with their error ranges. The compilation of data values was taken from Trenberth and Caron (2001) (see list of references therein for estimates of Atlantic and Pacific heat transport). 
(a) Pre-industrial $\Delta^{14} \mathrm{C}(\%)$
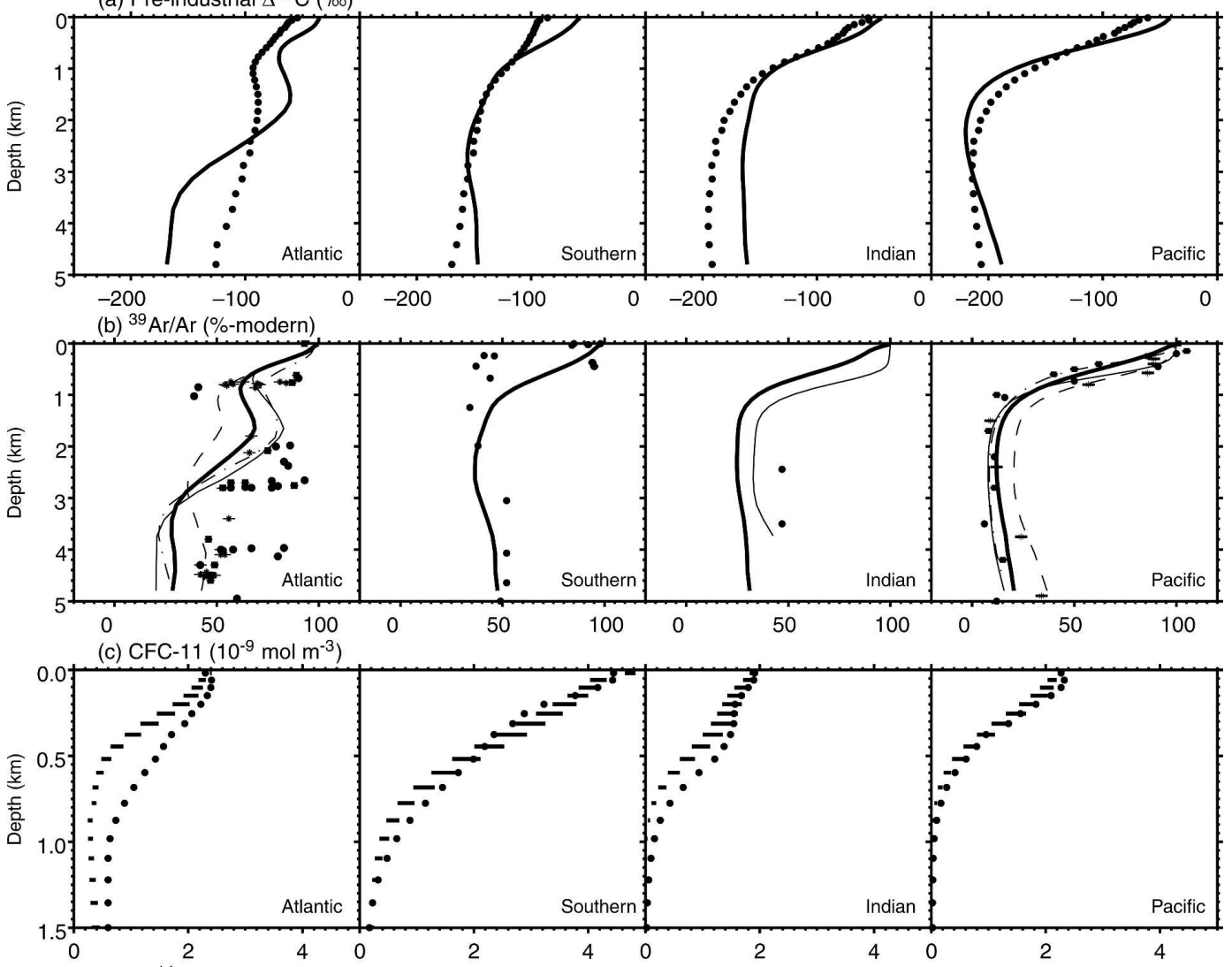

(d) $\Delta \Delta^{14} \mathrm{C}(\%)$

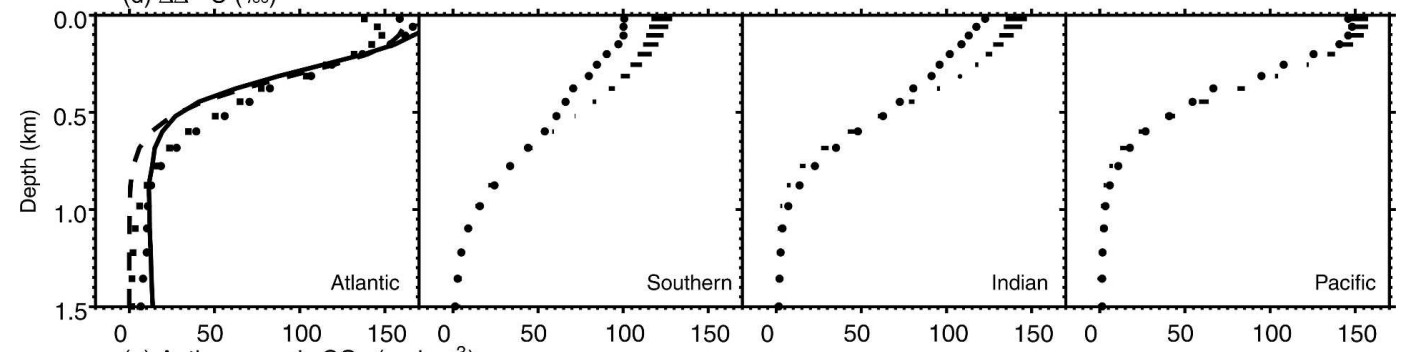

(e) Anthropogenic $\mathrm{CO}_{2}\left(\mathrm{~mol} \mathrm{~m}^{-3}\right)$

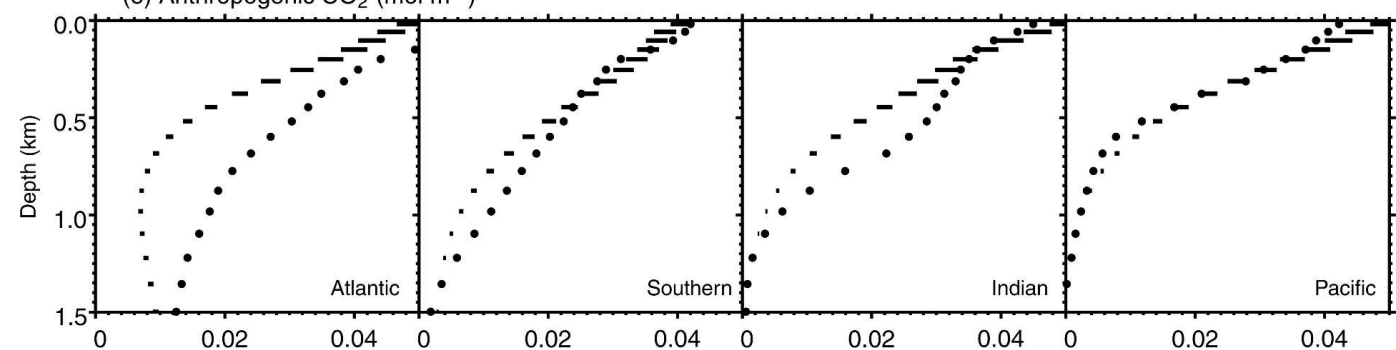

FIG. 10. Simulated (bold lines) vs data-based basin-averaged vertical profiles for the Atlantic, Pacific, and Indian Oceans (all north of $33.7^{\circ} \mathrm{S}$ ) and the Southern Ocean for (a) preindustrial $\Delta^{14} \mathrm{C}$, (b) ${ }^{39} \mathrm{Ar} / \mathrm{Ar}$, (c) CFC-11, (d) bomb-produced radiocarbon, and (e) anthropogenic carbon. Observation-based profiles (filled circles) were calculated from the GLODAP data (Key et al. 2004), except for ${ }^{39} \mathrm{Ar} / \mathrm{Ar}$. For ${ }^{39} \mathrm{Ar} / \mathrm{Ar}$ all available data (Rodriguez 1993) are shown with their 1- $\sigma$ uncertainty bar. Thin lines in the Atlantic denote simulated vertical mean ${ }^{39} \mathrm{Ar} / \mathrm{Ar}$ profiles for the western (solid), eastern (dash-dot), and southern Atlantic (dash). The near-surface ${ }^{39} \mathrm{Ar} / \mathrm{Ar}$ data with values around $45 \%$-modern were taken under the ice and are not representative for the ice-free area of the Southern Ocean. Only two ${ }^{39} \mathrm{Ar} / \mathrm{Ar}$ data points are available from the Indian Ocean; the thin line corresponds to the simulated profile at the grid cells covering the sampling location. Three ${ }^{39} \mathrm{Ar} / \mathrm{Ar}$ profiles were sampled in the Pacific near Hawaii (model: thin solid line; data: circles), and near the northwestern American coast (dash-dot, rectangles) and Tahiti (dash, stars). For CFC-11, bomb-produced radiocarbon, and anthropogenic carbon, the data used to compile the GLODAP climatology are sampled during different years. This introduces a small dating uncertainty. Model results are given as ranges (horizontal lines) obtained by sampling the model during the times of measurements in the individual basins, except for the bomb-produced radiocarbon profiles in the Atlantic, where the modeled profile for the northern Atlantic (solid, circles) is shown for the year 1981 and for the southern Atlantic (dash, squares) for the year 1988, respectively. 
(a) Atlantic: Model $\Delta^{14} \mathrm{C}$

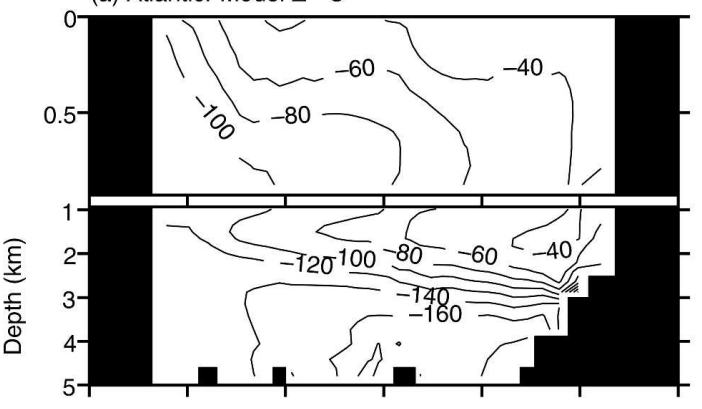

(c) Pacific: Model $\Delta^{14} \mathrm{C}$

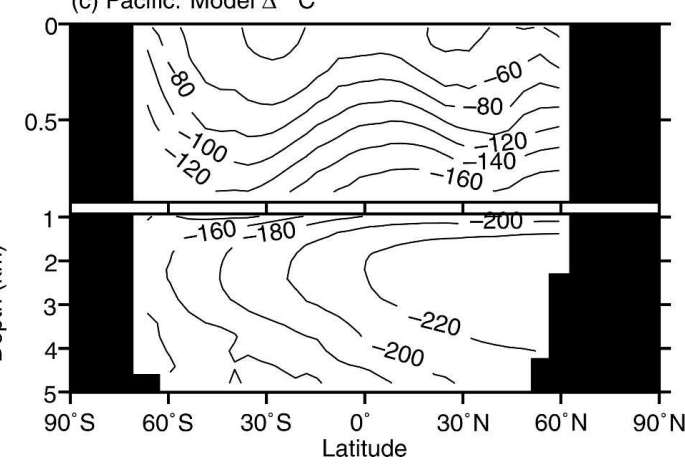

(b) Atlantic: Data-based $\Delta^{14} \mathrm{C}$

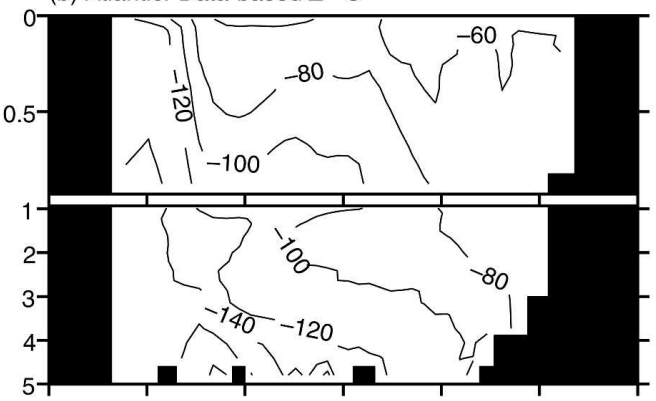

(d) Pacific: Data-based $\Delta^{14} \mathrm{C}$

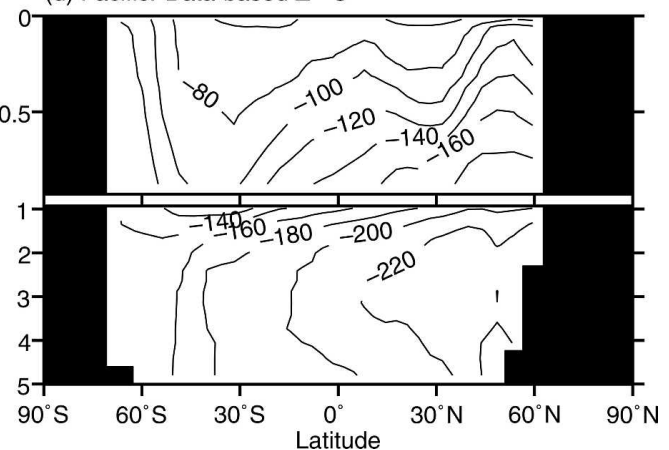

FIG. 11. (left) Simulated vs (right) observation-based zonally averaged preindustrial $\Delta{ }^{14} \mathrm{C}$ values (\%) in the (a), (b) Atlantic and (c), (d) Pacific.

in the upper ocean and in all basins. Modeled ratios are somewhat higher than observed in the surface ocean. This may point to a too-strong gas exchange rate in the model. We conclude that 1) the basin-averaged surfaceto-deep transport rates across the thermocline of the Pacific and in the upper $1500 \mathrm{~m}$ of the Southern Ocean are very realistic, 2) surface-to-deep transport is slightly too sluggish across the thermocline of the Indian Ocean, and 3) on average transport is too slow in the upper Atlantic.

Next, we turn to the radioisotopes basin mean profiles in the deep ocean. The data-based mean profiles are well simulated in the Pacific and Southern Ocean with slightly older-than-observed waters around 2000-m depth in the Pacific and younger-than-observed water ages below $3500 \mathrm{~m}$ in the Southern Ocean and the Pacific. The deep Indian Ocean appears to be ventilated somewhat too rapidly. The radiocarbon and argon profiles in the Atlantic clearly reveal that the penetration of NADW is too shallow. This leads to higherthan-observed radioisotopic signatures above $2500 \mathrm{~m}$ and to lower-than-observed radioisotopic signatures below.

The spatial distribution of natural radiocarbon is investigated in more detail to further analyze model strengths and weaknesses. The simulated radiocarbon distribution is generally in good agreement with the GLODAP climatology (Key et al. 2004) (Figs. 11, 12). Globally, the simulated spatial variability is about $12 \%$ higher than the observed variability, and the correlation coefficient between the simulated and data-based fields is 0.91 (Fig. 8).

Deviations between simulated and observed radiocarbon distributions are evident in zonal mean sections for the Atlantic and Pacific basins (Fig. 11). For example, the vertical radiocarbon gradient in the thermocline of the South Pacific is stronger in the simulation than in the data because the formation rate and northward extension of AAIW is too small. In the deep Pacific, isolines are bent too far northward compared to the data. This points to a somewhat too-vigorous flow of Southern Ocean water into the Pacific and out again. The penetration of young NADW is too shallow in the model. Instead of NADW, the deep North Atlantic is filled with radiocarbon-depleted AABW. There is a strong vertical gradient in the $\Delta^{14} \mathrm{C}$ field between 3000 and $2000 \mathrm{~m}$, in contrast to the data that show high $\Delta^{14} \mathrm{C}$ values down to the bottom in the North Atlantic.

A map of the radiocarbon distribution in the deep Atlantic and deep Pacific and Indian Oceans (Fig. 12) indicates that the model correctly reproduces the primary flow path of NADW in the western part of the 
(a) Model $\Delta^{14} \mathrm{C}$

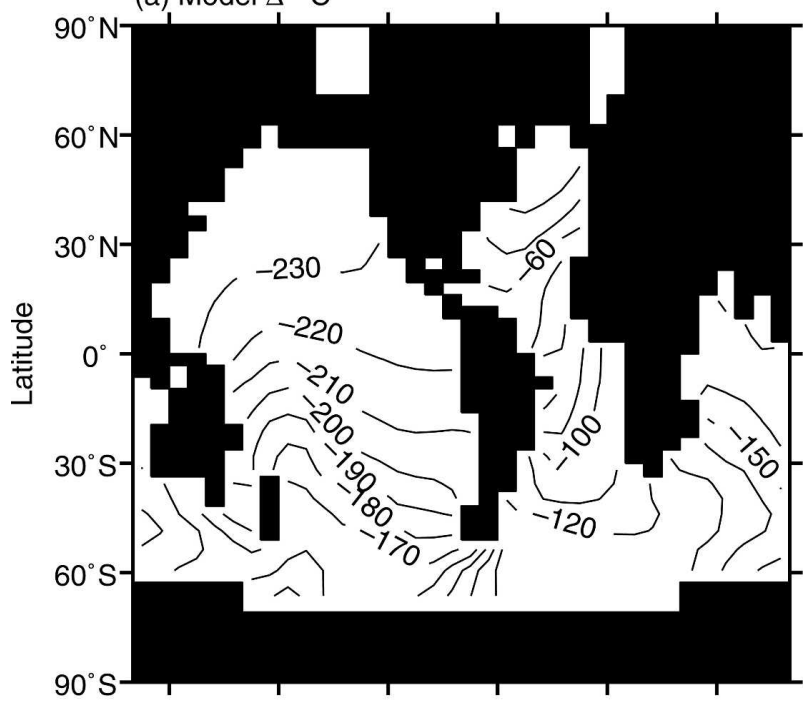

(b) Data-based $\Delta^{14} \mathrm{C}$

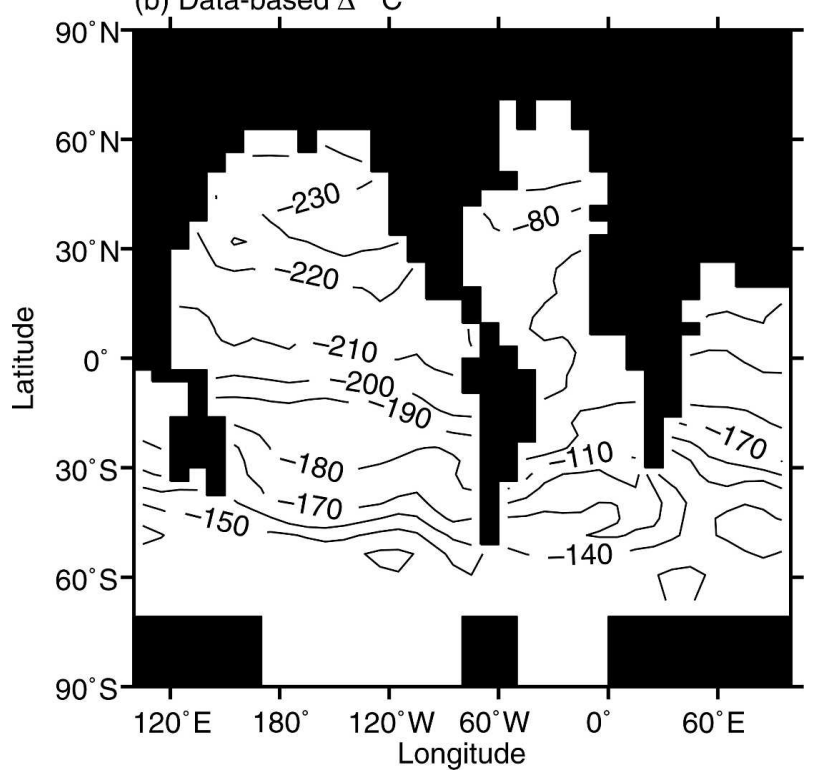

FIG. 12. (a) Simulated vs (b) observation-based distribution of $\Delta^{14} \mathrm{C}(\%)$ at a depth of around $2000 \mathrm{~m}$.

basin and that water from the south enters the Pacific and the Indian Ocean in the west of these basins. Radiocarbon is more depleted in the east than in the west in the Atlantic, the South Pacific, and the Indian Oceans, both in the model and the data. However, the east-west gradients are larger in the model than in the data. Simulated east-west radiocarbon gradients are also stronger than observed in the Southern Ocean. This reflects the fact that the strength of the circumpolar current and the Drake Passage throughflow are much less than that estimated from data (Ganachaud and Wunsch 2000).

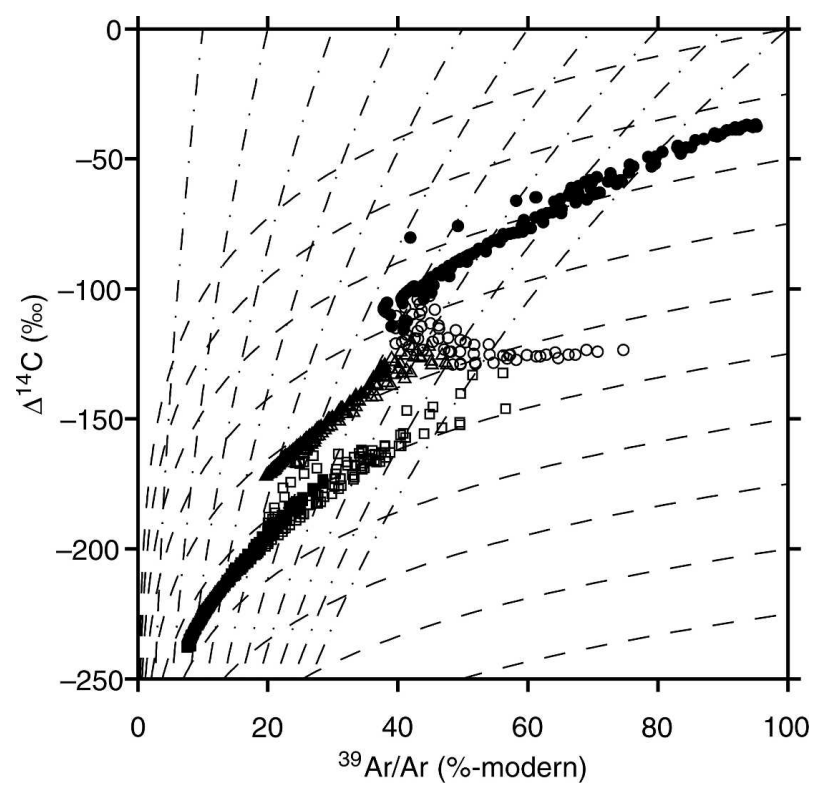

Fig. 13. Simulated $\Delta \Delta^{14} \mathrm{C}$ vs ${ }^{39} \mathrm{Ar} / \mathrm{Ar}$ values for all boxes at a depth of around $2000 \mathrm{~m}$ for the Atlantic (circles), Pacific (squares), and Indian (triangles) Oceans. Filled symbols are for regions north of $33.7^{\circ} \mathrm{S}$. The dashed lines show trajectories in $\Delta^{14} \mathrm{C}-{ }^{39} \mathrm{Ar} / \mathrm{Ar}$ space for pure advective transport; the dash-dotted lines are for pure diffusive transport (Maier-Reimer 1993).

Finally, the simulated relationship between $\Delta^{14} \mathrm{C}$ and the ${ }^{39} \mathrm{Ar} / \mathrm{Ar}$ ratios in the deep ocean is explored to illustrate the relative importance of advection versus diffusion in the model. Maier-Reimer (1993) pointed out that the slope of the relationship between $\Delta^{14} \mathrm{C}$ and the ${ }^{39} \mathrm{Ar} / \mathrm{Ar}$ ratios is different for advective transport than for diffusive transport. Figure 13 displays the relation between $\Delta^{14} \mathrm{C}$ and ${ }^{39} \mathrm{Ar} / \mathrm{Ar}$ for all model grid points at a depth of around $2000 \mathrm{~m}$. If tracers were transported by advection only, then all model points would fall on a line with a weak radiocarbon-to-argon slope (dashed lines in Fig. 13). On the other hand, the mixing lines would have a relatively steep slope if transport occurred by diffusion only (dash-dotted lines). The difference in slopes for the two transport mechanisms arises from the different decay rates of ${ }^{14} \mathrm{C}$ and ${ }^{39} \mathrm{Ar}$ (Maier-Reimer 1993). The plot shows that young, ${ }^{39} \mathrm{Ar}-$ and ${ }^{14} \mathrm{C}$-rich water is transported to the Southern Ocean where it mixes and from where it is further transported into the North Pacific and Indian Oceans. The mixing lines outside the Southern Ocean are somewhat more strongly aligned with the slopes for advective transport than for diffusive transport. We conclude that advection dominates horizontal transport in the deep ocean, but diffusion contributes to the overall transport in the deep ocean in this model. 
TABLE 3. CFC-11 inventories for the different ocean basins given in $10^{8} \mathrm{~mol}$. All model data show the uptake until 1995; data median is 1994 after Willey et al. (2004). Integrations were performed over the entire model domain to obtain the model inventories. Only grid cells with available data were considered for the calculations of the GLODAP inventories (third column).

\begin{tabular}{lccc}
\hline \hline \multicolumn{1}{c}{ Basin } & Model & GLODAP & Willey et al. (2004) \\
\hline Total & 5.4 & 5.5 & 5.5 \\
Atlantic & 1.9 & 2.0 & 1.9 \\
North Atlantic & 0.8 & 1.1 & \\
South Atlantic & 1.1 & 0.9 & \\
Pacific & 2.3 & 2.2 & 2.2 \\
Indian & 1.0 & 1.3 & 1.1 \\
Arctic & 0.2 & & 0.3 \\
\hline
\end{tabular}

\section{g. Simulated versus data-based inventories for CFC-11 and anthropogenic carbon}

The focus of this section is on the basin-averaged and specific (column) inventories of the transient tracers CFC-11, its partial pressure (pCFC-11), and anthropogenic carbon. We briefly examine the realism of upperocean model features such as the strength of the equatorial upwelling, midlatitude thermocline ventilation, and high-latitude convection based on these tracers.

The simulated global inventory of CFC-11 of $5.4 \times$ $10^{8}$ mol almost equals the data-based estimates from the GLODAP data and those from Willey et al. (2004) (Table 3). Simulated inventories for the Atlantic, Pacific, and Indian Oceans agree within $10 \%$ with the estimates of Willey et al. (2004). Model inventories are too low in the North Atlantic. The simulated distribution of CFC-11 column inventories reflects the observation of low inventories in the warm waters with low solubility in the tropical ocean and of high inventories in the cold waters with high solubility in the high latitudes. The solubility of CFC-11 varies by a factor of 5 between seawater at a temperature of $30^{\circ}$ and $0^{\circ} \mathrm{C}$. This strong temperature dependence of the solubility influences the spatial pattern of CFC-11 in addition to ocean transport.

Inventories of the partial pressure of CFC-11, pCFC11 , are predominantly governed by ocean transport and better reflect the distribution of anthropogenic carbon than CFC-11 inventories in molar units. In contrast to CFC-11 concentration, the partial pressure of CFC-11 is spatially relatively uniform in ocean surface water. This is a consequence of the close equilibrium between the atmosphere and the surface ocean because the equilibration time of the CFC-11 concentration in the surface layer with the atmosphere is about 1 month. The distribution of anthropogenic carbon is somewhat less uniform in the surface ocean than that of pCFC-11 because the Revelle factor varies by about $50 \%$ be- (a) Model

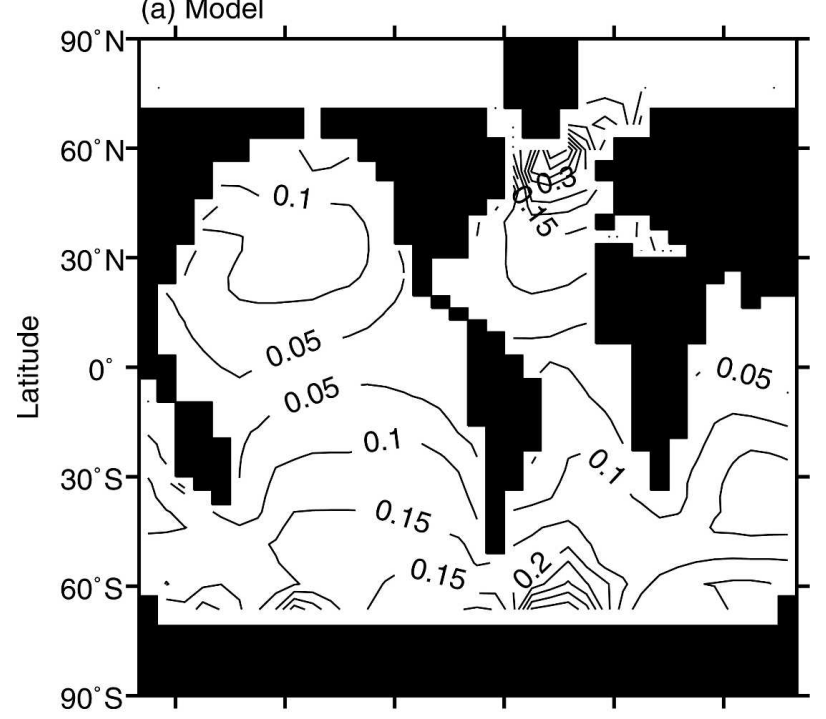

(b) Model - Data

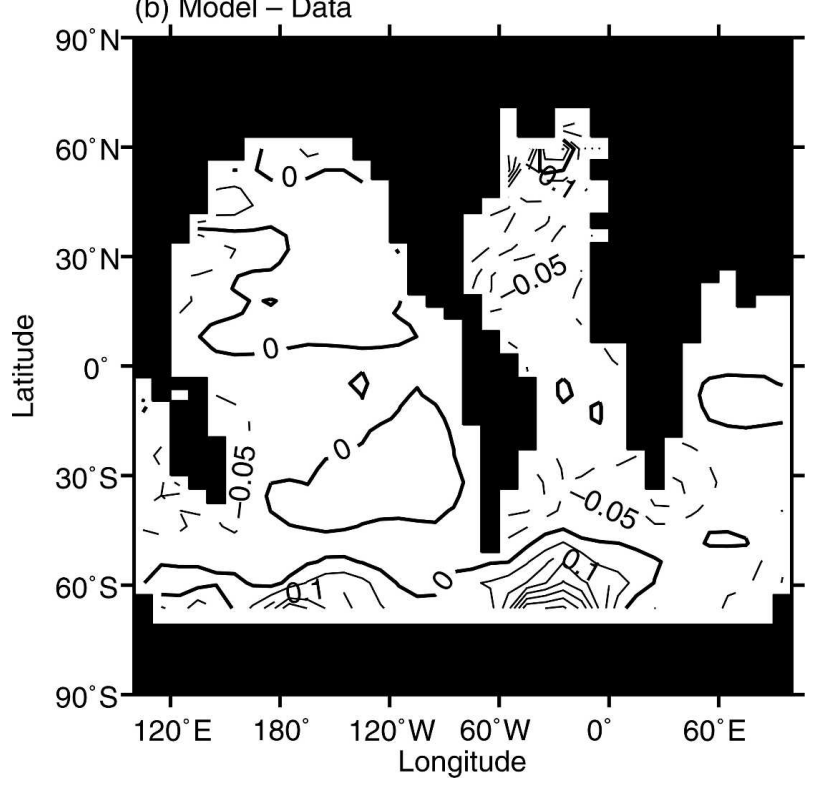

FIG. 14. (a) Simulated column inventory of pCFC-11 (ppm m) evaluated until 1995 and (b) the difference between model results and GLODAP data.

tween cold and warm waters and the equilibration time is about one year.

The specific pCFC-11 inventories (Figs. 14, 15) show a good agreement with the data-based estimates in the Indian and Pacific Oceans and the equatorial ocean. This suggests that the strength of equatorial upwelling and the ventilation time scales of the thermocline in the Pacific and Indian Ocean are modeled reasonably well. The simulated pCFC-11 inventories are clearly underestimated in the North Atlantic and overestimated in the high latitudes of the Southern Ocean. The insuffi- 


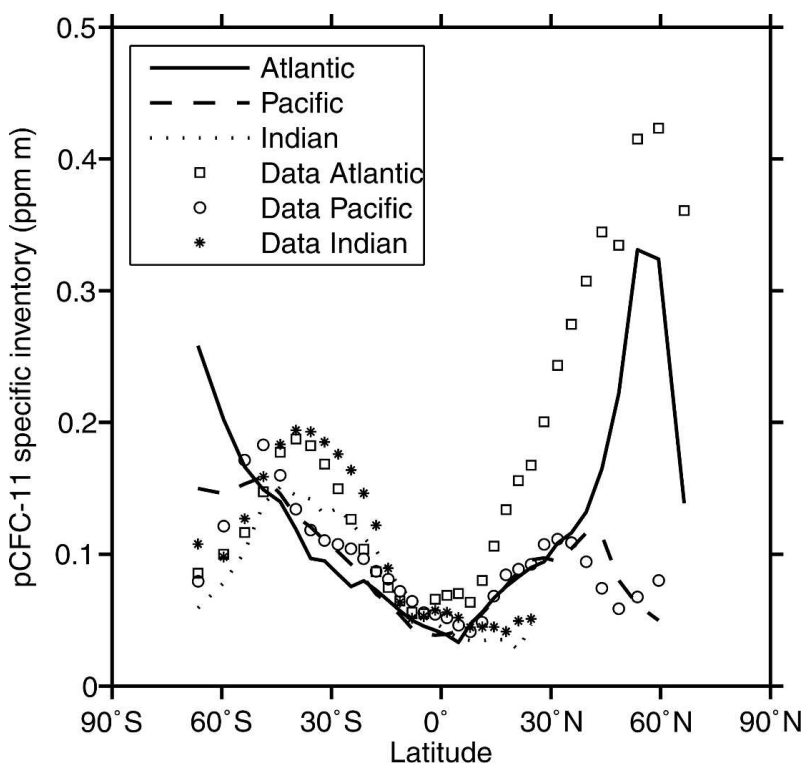

FIG. 15. Specific inventories of pCFC-11 (ppm m) vs latitude for the Atlantic (solid line, rectangles), Pacific (dashed line, circles), and Indian (dotted line, stars) Oceans. Model results (lines) are the simulated inventories until 1995. Observation-based estimates were calculated from the GLODAP data (symbols).

cient export of AAIW in the Atlantic is reflected by too-low pCFC-11 inventories around $40^{\circ} \mathrm{S}$. The total CFC-11 inventory in the Southern Ocean has been tuned to agree with observations. Nevertheless, CFC-11 and pCFC- 11 inventories are overestimated in the areas of intense deep-water formation south of $60^{\circ} \mathrm{S}$ around $50^{\circ}$ (Weddell Sea) and $175^{\circ} \mathrm{W}$ (Ross Sea). This is probably related to the substantially too-weak ACC that leads to larger-than-observed zonal pCFC-11 gradients in the Southern Ocean (as discussed earlier for radiocarbon).

Estimates of anthropogenic carbon inventories, that is, the excess carbon stored in the ocean since preindustrial time, have become available during the last decade (Gruber et al. 1996; Sabine et al. 1999, 2002; Lee et al. 2003; Sabine et al. 2004). The concentration of anthropogenic carbon cannot be estimated from direct measurements of dissolved inorganic carbon (DIC), but must be inferred from a range of tracers using specific assumptions on the carbon cycle and ocean transport. Uncertainties of data-based estimates of anthropogenic carbon are therefore inherently larger than those of CFC-11. The GLODAP database (Key et al. 2004) presents gridded fields of anthropogenic carbon that were deduced from measurements taken during the WOCE. These data, complemented by other published estimates (Sabine et al. 2004; Lee et al. 2003; Sabine et al. 2002, 1999), are used here for comparison with the model results (Table 4).
The simulated global inventory of anthropogenic carbon is 108.4 GtonC by 1995 . It agrees well with the data-based estimates from the GLODAP data of 106.8 GtonC and the estimate by Sabine et al. (2004) of 118 \pm 19 GtonC (Table 4). The latter estimates include inventories from marginal seas and other smaller areas not considered in the GLODAP data and in the model. Simulated basin mean inventories for the Indian and South Atlantic are in agreement with the data-based estimates within their uncertainties. The simulated inventory in the North Atlantic is lower than observationbased estimates, whereas the inventory in the Pacific is somewhat higher. The model strengths and shortcomings identified by analyzing the CFC- 11 distribution are also found for anthropogenic carbon (Fig. 16). Simulated and data-based fields agree reasonably well in the Pacific (north of $50^{\circ} \mathrm{S}$ ) and Indian Oceans, whereas the simulated inventories are too low in the North Atlantic and around $40^{\circ} \mathrm{S}$ in the South Atlantic and too high in the areas of the Ross and Weddell Seas. Again, the shortcomings in the Atlantic are related to a too-weak formation of NADW and a too-weak ventilation of the thermocline in the North Atlantic.

Net terrestrial and oceanic carbon uptake is compatible with estimates from atmospheric $\mathrm{O}_{2} / \mathrm{N}_{2}$ and $\mathrm{CO}_{2}$ measurements (Plattner et al. 2002; Manning and Keeling 2006) (Table 5). Simulated ocean uptake is 16.8, 18.9, and 19.7 GtonC for the 1980s, 1990s, and 19932003 , respectively. The inferred net terrestrial uptake

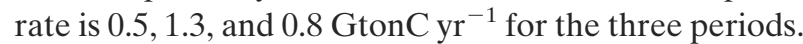
All these values are well within the range of the different data-based estimates. The simulated ocean uptake is comparable to the range of the OCMIP-2 models. Uptake rates obtained with the Bern3D model are at the lower end of the range spanned by those models from OCMIP-2 that matched the Indo-Pacific and Southern Ocean CFC-11 inventories within $15 \%$ and deep-water radiocarbon signatures within their $2 \sigma$ range (Matsumoto et al. 2004).

In conclusion, the comparison between simulated and observed pCFC-11 and anthropogenic carbon suggests reasonable thermocline ventilation in the Pacific and Indian Oceans and a reasonable strength of equatorial upwelling. AAIW formation is too weak in the South Atlantic, and NADW formation and thermocline ventilation are too weak in the North Atlantic. Simulated inventories and ventilation rates on the decadal time scale probed by CFC-11 and anthropogenic carbon are realistic for entire basins and globally.

\section{Discussion and conclusions}

A new cost-efficient three-dimensional seasonal ocean model has been developed using the dynamical 
TABLE 4. Simulated vs data-based anthropogenic carbon inventories for different basins (GtonC). Integrations were performed over the entire model domain and until the end of 1994 (until the end of 1993 for the Pacific Ocean) to obtain model inventories. Only grid cells with available data were considered for the calculations of the GLODAP inventories. The estimates of Sabine et al. (1999, 2002, 2004) and Lee et al. (2003) account for areas not covered in the GLODAP data and these inventories are generally larger than the inventories calculated from the GLODAP data. Uncertainties were taken from the publication by these authors. Numbers in parentheses give the periods of data sampling.

\begin{tabular}{lccc}
\hline \hline \multicolumn{1}{c}{ Basin } & Model & GLODAP & $\begin{array}{c}\text { Sabine et al. (2004); } \\
\text { Lee et al. (2003); } \\
\text { Sabine et al. (2002, 1999) }\end{array}$ \\
\hline Global & 108.4 & 106.8 & $118 \pm 19$ \\
North Atlantic & 20.0 & 23.2 & $28.4 \pm 4.7(90-98)$ \\
South Atlantic & 16.3 & 17.7 & $18.5 \pm 3.9(90-98)$ \\
Pacific & 47.9 & 41.8 & $44.5 \pm 5(91-96)$ \\
Indian & 21.2 & 24.2 & $20.3 \pm 3(94-96)$ \\
\hline
\end{tabular}

core of the model developed by Edwards and Marsh (2005). On a typical workstation, a simulation over 1000 $\mathrm{yr}$ requires much less than $1 \mathrm{~h}$ (with only temperature and salinity being transported). The Bern3D model is thus suited to perform multimillennia paleosimulations and large ensembles (hundreds) of simulations for Monte Carlo analyses (Knutti et al. 2002). The model has been set up to realistically represent the time scales of surface-to-deep transport of tracers. This makes it especially useful to study the uptake of heat, steric sea level rise, and anthropogenic carbon in global warming simulations as well as to address changes in the marine biogeochemical cycles involving tracer exchange across the sediment-ocean interface and between the abyss and the surface-ocean atmosphere system. For example, Siddall et al. (2005) apply the model to analyze the marine distribution of ${ }^{231} \mathrm{~Pa} /{ }^{230} \mathrm{Th}$, a paleoproxy for ocean transport rates. Muscheler et al. $(2005,2006)$ use the model together with a carbon-cycle component and a land biosphere model to infer radiocarbon production rates and the solar magnetic activity from the tree ring radiocarbon record. The model is also used to estimate regional air-sea fluxes of anthropogenic carbon dioxide in an ocean inversion study (Mikaloff Fletcher et al. 2006).

Structural model improvements compared to the original model of Edwards and Marsh (2005) include a separation of the representation of the Gent-McWilliams transport and of eddy diffusion along isopycnals and a new convective scheme. These changes were sufficient to achieve a realistic CFC-11 inventory and a realistic $\Delta{ }^{14} \mathrm{C}$ signature in the Southern Ocean. A high vertical resolution of 32 layers permits the simulation of a deep

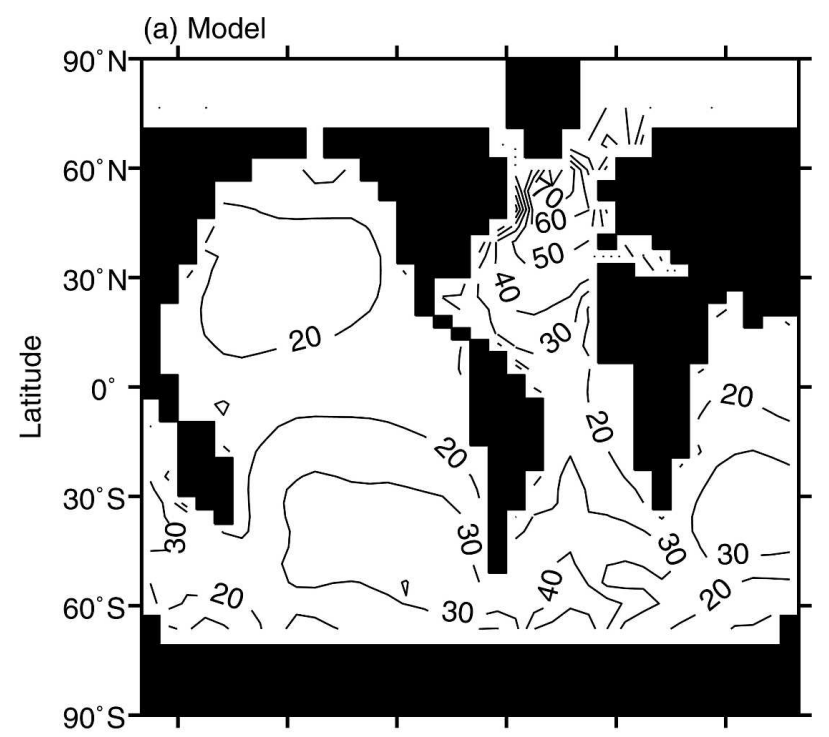

(b) Model - Data

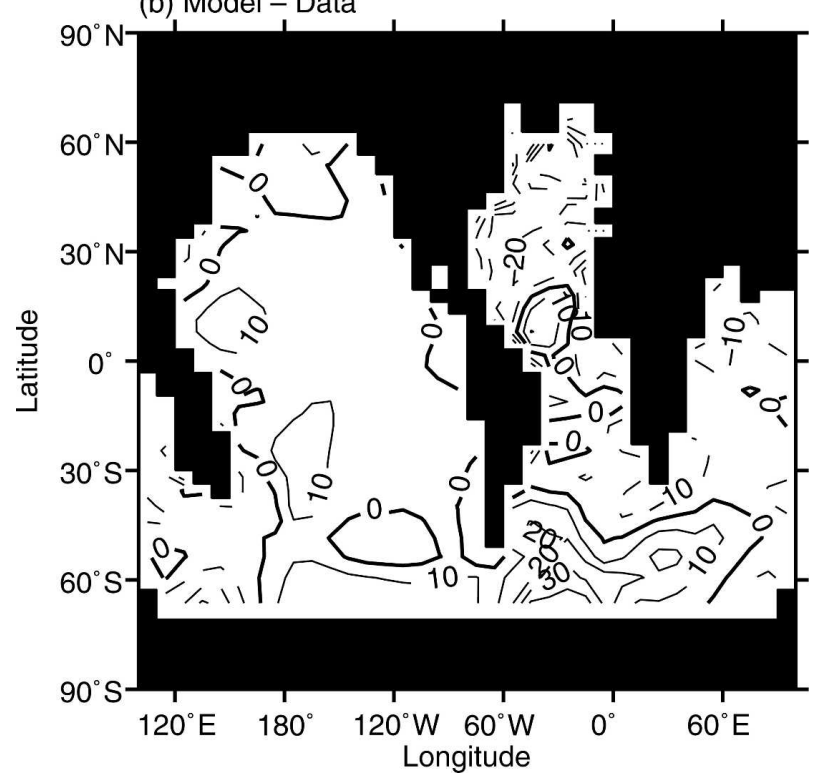

FIG. 16. (a) Column inventory of anthropogenic carbon $\left(\mathrm{mol} \mathrm{m}^{-2}\right)$ simulated until 1995 and (b) the difference between model results and GLODAP data.

return flow from the Pacific into the Southern Ocean and avoids unrealistically high rates of deep equatorial upwelling. This is important for simulations of the marine carbon cycle to avoid equatorial nutrient trapping. Hargreaves et al. (2004) tuned the eight-layer model of Edwards and Marsh (2005) to reproduce realistic deep ocean temperatures when coupled to simple atmosphere and sea ice models. However, in their version deep equatorial upwelling in the Pacific is very large (13 Sv), and mixing and overturning in the Southern Ocean appears to be too vigorous. How the various dynamical 
TABLE 5. Modeled changes in carbon inventories in comparison with estimates from Plattner et al. (2002, herein P102) and Manning and Keeling (2006, herein Ma06) (all quantities in GtonC).

\begin{tabular}{|c|c|c|c|c|c|c|c|c|}
\hline & \multicolumn{2}{|c|}{$1980 \mathrm{~s}$} & \multicolumn{3}{|c|}{$1990 \mathrm{~s}$} & \multicolumn{2}{|c|}{ 1993-2003 } & \multirow{2}{*}{$\frac{1700-2004}{\text { Model }^{*}}$} \\
\hline & Model & $\mathrm{P} 102$ & Model & $\mathrm{P} 102$ & Ma06 & Model & Ma06 & \\
\hline Atmospheric increase & \multicolumn{2}{|c|}{32.9} & \multicolumn{3}{|c|}{31.6} & \multicolumn{2}{|c|}{37.4} & 209.8 \\
\hline Fossil emissions & \multicolumn{2}{|c|}{54.5} & \multicolumn{3}{|c|}{63.5} & \multicolumn{2}{|c|}{64.8} & 303.4 \\
\hline Ocean-atmosphere & -16.8 & $-17 \pm 6$ & -18.9 & $-24 \pm 7$ & $-19 \pm 6$ & -19.7 & $-22.4 \pm 6.1$ & -130.7 \\
\hline Land-atmosphere & -4.8 & $-4 \pm 7$ & -13.0 & $-7 \pm 8$ & $-12 \pm 8$ & -7.7 & $-5.1 \pm 7.4$ & 36.5 \\
\hline
\end{tabular}

* In contrast to the other simulations, the reference value for the preindustrial $\mathrm{pCO}_{2}$ was set to 276.65 ppm, resulting in a no-flux situation in the year 1700. This results in an upward shift of about 4 GtonC in oceanic $\mathrm{CO}_{2}$ inventory in the recent decades. For the calculation of the fossil emissions a fixed increase at the end of available data is assumed.

differences between these two models contribute to the differences in oceanic response, however, remains to be determined.

The model is forced with seasonal boundary conditions for surface temperature, salinity, and wind stress. Strong seasonal variations in the Ekman cells were found comparable to results with other models (Schmittner and Stocker 2001; Nakano et al. 1999). Saenko et al. (2002) pointed out the importance of sea ice dynamics for the formation of intermediate and deep-water mass formation and the uptake of CFCs. Here, we restore toward prescribed values of sea surface salinity, partially accounting for the freshwater fluxes associated with sea ice dynamics.

Model weaknesses requiring further improvements include a too-weak formation of AAIW and of NADW. The penetration of NADW is too shallow and the deep North Atlantic below about $3000 \mathrm{~m}$ is filled with water from the south instead of NADW. The problem of simulating a realistic penetration of NADW is shared with more sophisticated models (e.g., Guilderson et al. 2000). Horizontal model resolution has been kept coarse and simulated surface gyre transport is much weaker than observed.

Surface-to-deep tracer transport by explicit diapycnal diffusion is very small and vertical tracer exchange is dominated by advective processes. How much spurious vertical numerical diffusion and diapycnal leakage is present is, however, difficult to assess and remains a subject for future studies. However, the solution for the large-scale circulation converges for a high vertical resolution (Fig. 4), suggesting that numerical diffusivity in the vertical direction does not play a dominant role.

The model performance is comparable to the general circulation ocean models participating in the OCMIP-2 project for a range of metrics (Matsumoto et al. 2004; Doney et al. 2004; Dutay et al. 2002). The characteristic time scales of tracer uptake in the upper ocean and of the transport across the thermocline and the ventilation of the deep ocean are close to data-based estimates.
Meridional heat transport, although somewhat low in the North Atlantic, is comparable to data-based estimates. Water mass characteristics are well matched in most regions and root-mean-square differences between modeled and observed temperature and salinity fields are small $(1 \mathrm{~K}, 0.2 \mathrm{psu})$. Inventories and basinaveraged profiles of anthropogenic carbon and CFC-11 agree well with data-based estimates for the Southern, Pacific, Indian, and global ocean, and results for natural and bomb-produced radiocarbon and for ${ }^{39} \mathrm{Ar} / \mathrm{Ar}$ are largely consistent with observations.

Acknowledgments. This study was supported by grants of the Swiss National Science Foundation and by NCCR Climate of the Swiss National Science Foundation through a fellowship to NRE. We thank T. J. Conway for providing recent globally averaged $\mathrm{CO}_{2}$ data and G.-K. Plattner for helpful comments.

\section{REFERENCES}

Bryan, K., 1969: A numerical method for the study of the circulation of the world ocean. J. Comput. Phys., 4, 347-376.

Collins, W. D., and Coauthors, 2006: The Community Climate System Model (CCSM3). J. Climate, 19, 2122-2143.

Doney, S. C., and Coauthors, 2004: Evaluating global ocean carbon models: The importance of realistic physics. Global Biogeochem. Cycles, 18, GB3017, doi:10.1029/2003GB002150.

Dutay, J.-C., and Coauthors, 2002: Evaluation of ocean model ventilation with CFC-11: Comparison of 13 global ocean models. Ocean Modell., 4, 89-120.

Edwards, N. R., and J. G. Shepherd, 2001: Multiple thermohaline states due to variable diffusivity in a hierarchy of simple models. Ocean Modell., 3, 67-94.

- - and R. Marsh, 2005: Uncertainties due to transportparameter sensitivity in an efficient 3-d ocean-climate model. Climate Dyn., 24, 415-433.

—, A. J. Willmott, and P. D. Killworth, 1998: On the role of topography and wind stress on the stability of the thermohaline circulation. J. Phys. Oceanogr., 28, 756-778.

England, M. H., and E. Maier-Reimer, 2001: Using chemical tracers to assess ocean models. Rev. Geophys., 39, 29-70.

Enting, I. G., 1987: On the use of smoothing splines to filter $\mathrm{CO}_{2}$ data. J. Geophys. Res., 92, 10 977-10 984. 
- T. M. L. Wigley, and M. Heimann, 1994: Future emissions and concentrations of carbon dioxide: Key ocean/ atmosphere/land analyses. Division of Atmospheric Research, CSIRO, Tech. Rep. 31, 118 pp.

Etheridge, D. M., L. P. Steele, R. L. Langenfelds, R. J. Francey, J. Barnola, and V. I. Morgan, 1996: Natural and anthropogenic changes in atmospheric $\mathrm{CO}_{2}$ over the last 1000 years from air in Antarctic ice and firn. J. Geophys. Res., 101, 4115-4128.

Fiadeiro, M. E., and G. Veronis, 1977: On weighted-mean schemes for the finite-difference approximation to the advection-diffusion equation. Tellus, 29, 512-522.

Ganachaud, A., and C. Wunsch, 2000: Improved estimates of global ocean circulation, heat transport and mixing from hydrographic data. Nature, 408, 453-457.

Gent, P. R., J. Willebrand, T. J. McDougall, and J. C. McWilliams, 1995: Parameterizing eddy-induced tracer transports in ocean circulation models. J. Phys. Oceanogr., 25, 463-474.

Griffies, S. M., 1998: The Gent-McWilliams skew flux. J. Phys. Oceanogr., 28, 831-841.

Gruber, N., J. L. Sarmiento, and T. F. Stocker, 1996: An improved method for detecting anthropogenic $\mathrm{CO}_{2}$ in the oceans. Global Biogeochem. Cycles, 10, 809-837.

Guilderson, T. P., K. Caldeira, and P. B. Duffy, 2000: Radiocarbon as a diagnostic tracer in ocean and carbon cycle modeling. Global Biogeochem. Cycles, 14, 887-902.

Hargreaves, J. C., J. D. Annan, N. R. Edwards, and R. Marsh, 2004: An efficient climate forecasting method using an intermediate complexity Earth System Model and the ensemble Kalman filter. Climate Dyn., 23, 745-760.

Hirst, A. C., and W. Cai, 1994: Sensitivity of a World Ocean GCM to changes in subsurface mixing parameterization. J. Phys. Oceanogr., 24, 1256-1279.

Kalnay, E., and Coauthors, 1996: The NCEP/NCAR 40-Year Reanalysis Project. Bull. Amer. Meteor. Soc., 77, 437-471.

Keeling, C. D., and T. P. Whorf, 1994: Atmospheric $\mathrm{CO}_{2}$ records from sites in the SIO network. Trends '93: A Compendium of Data on Global Change, T. Boden et al., Eds., Carbon Dioxide Information Analysis Center, Oak Ridge National Laboratory, 16-26.

Key, R. M., P. D. Quay, G. A. Jones, A. P. McNichol, K. F. von Reden, and R. J. Schneider, 1996: WOCE AMS radiocarbon I: Pacific Ocean results (P6, P16 and P17). Radiocarbon, 38, $425-518$.

— Results from Global Data Analysis Project (GLODAP). Global Biogeochem. Cycles, 18, GB4031, doi:10.1029/ $2004 \mathrm{~GB} 002247$.

Knutti, R., T. F. Stocker, F. Joos, and G. Plattner, 2002: Constraints on radiative forcing and future climate change from observations and climate model ensembles. Nature, 416, 719723.

Lee, K., and Coauthors, 2003: An updated anthropogenic $\mathrm{CO}_{2}$ inventory in the Atlantic Ocean. Global Biogeochem. Cycles, 17, 1116, doi:10.1029/2003GB002067.

Levitus, S., and T. Boyer, 1994: Temperature. Vol. 4, World Ocean Atlas 1994, NOAA Atlas NESDIS4, 117 pp.

—, R. Burgett, and T. Boyer, 1994: Salinity. Vol. 3, World Ocean Atlas 1994, NOAA Atlas NESDIS3, 99 pp.

Maier-Reimer, E., 1993: Geochemical cycles in an ocean general circulation model. Preindustrial tracer distributions. Global Biogeochem. Cycles, 7, 645-677.

__ U. Mikolajewicz, and K. Hasselmann, 1993: Mean circula- tion of the Hamburg LSG OGCM and its sensitivity to the thermohaline surface forcing. J. Phys. Oceanogr., 23, 731757.

Manning, A. C., and R. F. Keeling, 2006: Global oceanic and land biotic carbon sinks from the Scripps atmospheric oxygen flask sampling network. Tellus, 58, 95-116.

Marchal, O., T. F. Stocker, F. Joos, A. Indermühle, T. Blunier, and J. Tschumi, 1999: Modelling the concentration of atmospheric $\mathrm{CO}_{2}$ during the Younger Dryas climate event. Climate Dyn., 15, 341-354.

Matsumoto, K., and Coauthors, 2004: Evaluation of ocean carbon cycle models with data-based metrics. Geophys. Res. Lett., 31, L07303, doi:10.1029/2003GL018970.

Mikaloff Fletcher, S. E., and Coauthors, 2006: Inverse estimates of anthropogenic $\mathrm{CO}_{2}$ uptake, transport, and storage by the ocean. Global Biogeochem. Cycles, 20, GB2002, doi:10.1029/ 2005GB002530.

Muscheler, R., F. Joos, S. A. Müller, and I. Snowball, 2005: How unusual is today's solar activity? Nature, 436, E3-E4.

J. Beer, S. A. Müller, M. Vonmoos, and I. Snowball, 2006: Changes in solar activity during the last 1000 years inferred from radionuclide records. Quat. Sci. Rev., in press.

Nakano, H., R. Furue, and N. Suginohara, 1999: Effect of seasonal forcing on global circulation in a world ocean general circulation model. Climate Dyn., 15, 491-502.

Orr, J. C., 1999: On ocean carbon-cycle model comparison. Tellus, 51B, 509-510.

— J. Jutay, R. Najjar, J. Bullister, and P. Brockmann, 1999a: CFC HOWTO. OCMIP Internal Rep., 12 pp. [Available online at http://www.ipsl.jussieu.fr/OCMIP/phase2/simulations/ CFC/HOWTO-CFC.html.]

—_, R. Najjar, C. L. Sabine, and F. Joos, 1999b: Abiotic HOWTO. OCMIP Internal Rep., 25 pp. [Available online at http://www.ipsl.jussieu.fr/OCMIP/phase2/simulations/Abiotic/ HOWTO-Abiotic.html.]

Plattner, G., F. Joos, T. F. Stocker, and O. Marchal, 2001: Feedback mechanisms and sensitivities of ocean carbon uptake under global warming. Tellus, 53B, 564-592.

,-- , and — 2002: Revision of the global carbon budget due to changing air-sea oxygen fluxes. Global Biogeochem. Cycles, 16, 1096, doi:10.1029/2001GB001746.

Redi, M. H., 1982: Oceanic isopycnal mixing by coordinate rotation. J. Phys. Oceanogr., 12, 1154-1158.

Rodriguez, J., 1993: Beiträge zur Verteilung von ${ }^{39}$ Ar im Atlantik. Ph.D. thesis, University of Bern, 125 pp.

Sabine, C. L., R. M. Key, K. M. Johnson, F. J. Millero, A. Poisson, J. L. Sarmiento, D. W. R. Wallace, and C. D. Winn, 1999: Anthropogenic $\mathrm{CO}_{2}$ inventory of the Indian Ocean. Global Biogeochem. Cycles, 13, 179-198.

— the Pacific Ocean. Global Biogeochem. Cycles, 16, 1083, doi:10.1029/2001GB001639.

_ , and Coauthors, 2004: The oceanic sink for anthropogenic CO2. Science, 305, 367-371.

Saenko, O. A., A. Schmittner, and A. J. Weaver, 2002: On the role of wind-driven sea ice motion on ocean ventilation. J. Phys. Oceanogr., 32, 3376-3395.

Sarmiento, J. L., J. C. Orr, and U. Siegenthaler, 1992: A perturbation simulation of $\mathrm{CO}_{2}$ uptake in an ocean general circulation model. J. Geophys. Res., 97, 3621-3645.

Schmittner, A., and T. F. Stocker, 2001: A seasonally forced 
ocean-atmosphere model for paleo-climate studies. Climate Dyn., 14, 1055-1068.

Siddall, M., G. M. Henderson, N. R. Edwards, M. Frank, S. A. Müller, T. F. Stocker, and F. Joos, 2005: ${ }^{231} \mathrm{~Pa} /{ }^{230} \mathrm{Th}$ fractionation by ocean transport, biogenic particle flux and particle type. Earth Planet. Sci. Lett., 237, 135-155.

Siegenthaler, U., and T. Wenk, 1984: Rapid atmospheric $\mathrm{CO}_{2}$ variations and ocean circulation. Nature, 308, 624-626.

—_ and F. Joos, 1992: Use of a simple model for studying oceanic tracer distributions and the global carbon cycle. Tellus, 44B, 186-207.

and Coauthors, 2005: Supporting evidence from the EPICA Dronning Maud Land ice core for atmospheric $\mathrm{CO}_{2}$ changes during the past millennium. Tellus, 57B, 51-57.

Stocker, T. F., D. G. Wright, and L. A. Mysak, 1992: A zonally averaged, coupled ocean-atmosphere model for paleoclimate studies. J. Climate, 5, 773-797.

Toggweiler, J. R., K. Dixon, and K. Bryan, 1989a: Simulations of radiocarbon in a coarse-resolution world ocean model. 1: Steady state prebomb distributions. J. Geophys. Res., 94, 8217-8242.

- —, and $-1989 \mathrm{~b}$ : Simulations of radiocarbon in a coarse-resolution world ocean model. 2: Distribution of bomb-produced carbon 14. J. Geophys. Res., 94, 8243-8264.

Trenberth, K. E., and J. M. Caron, 2001: Estimates of meridional atmosphere and ocean heat transports. J. Climate, 14, 3433 3443 .

Wanninkhof, R., 1992: Relationship between wind speed and gas exchange over the ocean. J. Geophys. Res., 97, 7373-7382.

Warner, M. J., and R. F. Weiss, 1985: Solubilities of cholorfluorocarbon-11 and chlorofluorocarbon-12 in water and seawater. Deep Sea Res., 32A, 1485-1497.

Weaver, A. J., and E. S. Sarachick, 1990: On the importance of vertical resolution in certain ocean general circulation models. J. Phys. Oceanogr., 20, 600-609.

Weiss, R. F., 1970: The solubility of nitrogen, oxygen and argon in water and seawater. Deep-Sea Res., 17, 721-735.

- , 1974: Carbon dioxide in water and seawater, the solubility of a non-ideal gas. Mar. Chem., 2, 203-215.

Willey, D. A., R. A. Fine, R. E. Sonnerup, J. L. Bullister, W. M. Smethie Jr., and M. J. Warner, 2004: Global oceanic chlorofluorocarbon inventory. Geophys. Res. Lett., 31, L01303, doi:10.1029/2003GL018816.

Winton, M., and E. S. Sarachik, 1993: Thermohaline oscillations induced by strong steady salinity forcing of ocean generalcirculation models. J. Phys. Oceanogr., 23, 1389-1410.

Wright, D. G., and T. F. Stocker, 1991: A zonally averaged ocean model for the thermohaline circulation. Part I: Model development and flow dynamics. J. Phys. Oceanogr., 21, 17131724. 